UNIVERSIDADE DE SÃO PAULO

FACULDADE DE ZOOTECNIA E ENGENHARIA DE ALIMENTOS

PAULO DE MÉO FILHO

CONSUMO, DESEMPENHO, EMISSÃO DE METANO E CARACTERÍSTICAS DE CARCAÇA DE NOVILHOS DA RAÇA CANCHIM RECRIADOS A PASTO E TERMINADOS EM CONFINAMENTO 
Paulo de Méo Filho

\section{CONSUMO, DESEMPENHO, EMISSÃO DE METANO E CARACTERÍSTICAS DE CARCAÇA DE NOVILHOS DA RAÇA CANCHIM RECRIADOS A PASTO E TERMINADOS EM CONFINAMENTO \\ (Versão Corrigida)}

Dissertação apresentada à Faculdade de Zootecnia e Engenharia de Alimentos da Universidade de São Paulo, como parte dos requisitos para a obtenção do Título de Mestre em Zootecnia.

Área de Concentração: Qualidade e Produtividade Animal

Orientador: Prof. Dr. Ives Cláudio da Silva Bueno 
Ficha catalográfica elaborada pelo

Serviço de Biblioteca e Informação, FZEA/USP, com

os dados fornecidos pelo(a) autor(a)

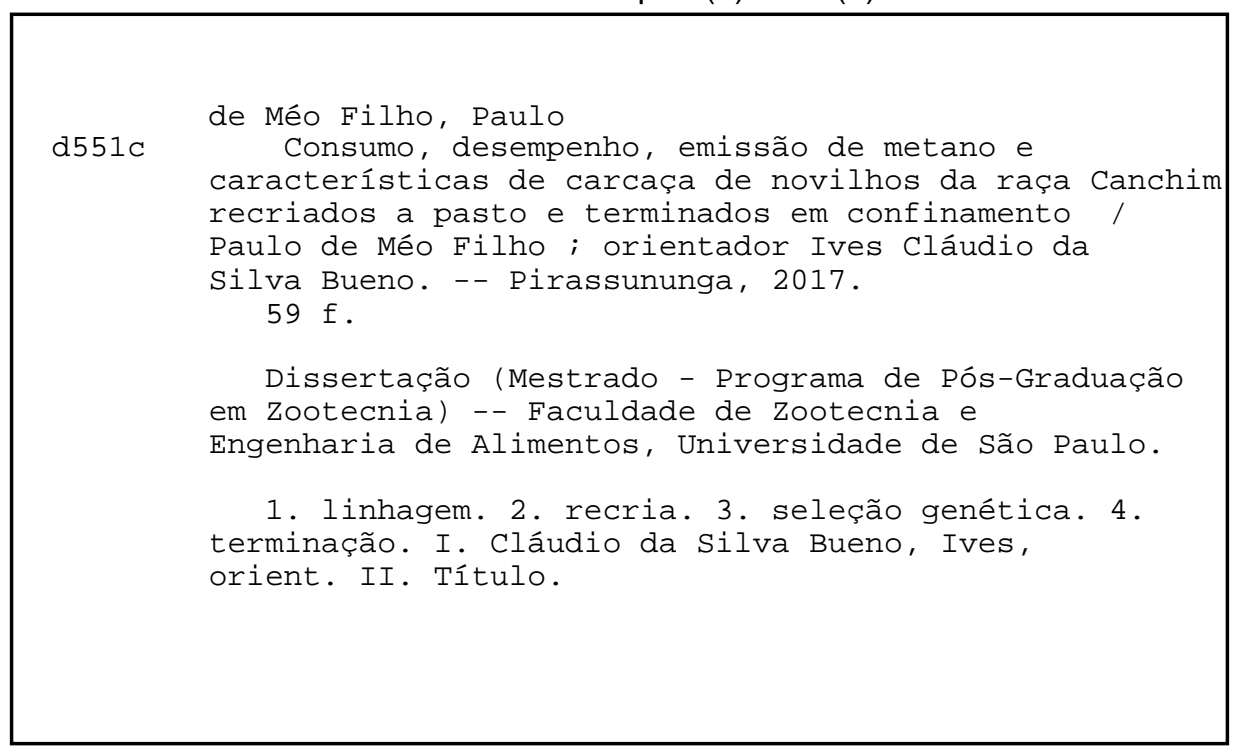

Permitida a cópia total ou parcial deste documento, desde que citada a fonte - o autor 
PAULO DE MÉO FILHO

\section{CONSUMO, DESEMPENHO, EMISSÃO DE METANO E CARACTERÍSTICAS DE CARCAÇA DE NOVILHOS DA RAÇA CANCHIM RECRIADOS A PASTO E TERMINADOS EM CONFINAMENTO}

Dissertação apresentada à Faculdade de Zootecnia e Engenharia de Alimentos da Universidade de São Paulo, como parte dos requisitos para a obtenção do Título de Mestre em Ciências.

Área de Concentração: Qualidade e Produtividade Animal

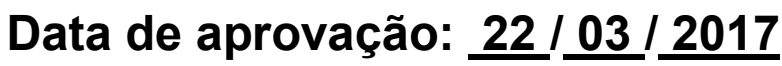

Banca Examinadora:

Ives Cláudio da Silva Bueno - Presidente da Banca Examinadora Prof. Dr. Universidade de São Paulo - Faculdade de Zootecnia e Engenharia de Alimentos - Orientador (a).

Cintia Righetti Marcondes

Dra. Empresa Brasileira de Pesquisa Agropecuária - EMBRAPA (Pecuária Sudeste).

Ricardo Andrade Reis

Prof. Dr. Universidade Estadual Paulista - Faculdade de Ciências Agrárias e Veterinária. 
Aos meus pais Regina e Paulinho, que com dedicação, amor, exemplo de casal e família, são responsáveis por tudo que conquistei em minha vida.

A minha Namorada Monalisa por todo o amor e por ser fundamental e estar ao meu lado desde o início desta caminhada que hoje se conclui. 


\section{AGRADECIMENTOS}

A minha mãe Regina, por todo o amor, por suas orações, por estar ao meu lado continuando a me incentivar como toda a vida e fazer de tudo para que eu seja feliz e conquiste os meus objetivos.

Ao meu pai Paulinho, (in memorian) por ter vivido pela felicidade de nossa família, por me ensinar e ser exemplo de valores e caráter, e por tudo que dedicou em sua vida por minha felicidade, crescimento pessoal e intelectual.

A minha namorada Monalisa, por ter me mostrado que era sim possível seguir este caminho, por todo amor, carinho, apoio e paciência.

As minhas irmãs Rita, Marita e Fernanda, por toda a torcida, amor e apoio mesmo que o caminho que optei por seguir sacrifique tanto o tempo que passávamos juntos.

Aos meus tios, Vera e Pedro, Ines (Bó) e Santana (Bô) que sempre estiveram presentes em minha vida, oferecendo amor, apoio, incentivo, e torcendo pelo meu sucesso.

Ao Dr. Alexandre Berndt, pela convivência, valores, ensinamentos, paciência e apoio, desde minha chegada na Embrapa Pecuária Sudeste e por toda a orientação nesse período que se conclui.

Ao meu orientador Prof. Dr. Ives Cáudio da Silva Bueno, pela confiança desde o início, pelo apoio e ensinamentos também fundamentais a minha formação.

Ao Prof. Dr. Paulo Mazza, por todo ensinamento, paciência e ajuda com os dados e a estatística.

A Dra. Cintia Righetti Marcondes por toda ajuda, atenção e paciência desde o delineamento do experimento, até a conclusão deste trabalho.

Ao Dr. André de Faria Pedroso, pelos ensinamentos, acompanhamento, e atenção comigo e com este trabalho principalmente no que se diz a pastagens.

Aos meus amigos de Embrapa, Amanda, Daniella, Jean, Kauê, Leandro, Mariana, Jéssica, Maria Ligia, Bárbara e Leticia, por toda a ajuda, companheirismo, ensinamentos e amizade.

As meninas do LFR (Laboratório de Fermentabilidade Ruminal), pela amizade e confiança mesmo no pouco tempo que pudemos conviver.

A toda equipe técnica da Embrapa, pesquisadores, analistas e técnicos de campo, por toda ajuda, dedicação e apoio.

A Faculdade de Zootecnia e Engenharia de Alimentos, por ser fundamental a minha formação profissional desde o início de minha graduação, com tanta qualidade, estrutura e renome.

A EMBRAPA - Empresa Brasileira de Pesquisa Agropecuária, pelo acolhimento, e base desde meu estágio de conclusão de curso na graduação. 
A CAPES - Coordenação de Aperfeiçoamento de Pessoal de Nível Superior, pelo auxílio com a bolsa de estudos do edital CAPES/EMBRAPA 03/2014. 


\section{RESUMO}

MÉO FILHO, P. Consumo, desempenho, emissão de metano e características de carcaça de novilhos da raça Canchim recriados a pasto e terminados em confinamento. 2017. 58 f. Dissertação (Mestrado) - Faculdade de Zootecnia e Engenharia de Alimentos, Universidade de São Paulo, Pirassununga, 2017.

O presente trabalho teve como objetivo avaliar novilhos resultantes da seleção genética de diferentes linhagens da raça Canchim (5/8 Charolês, 3/8 Zebu), recriados a pasto e terminados em confinamento, em relação ao consumo alimentar, desempenho, emissão de metano entérico, características de carcaça e cortes cárneos. O experimento foi desenvolvido na Empresa Brasileira de Pesquisa Agropecuária, unidade Pecuária Sudeste, São Carlos/SP. Foram utilizados 46 novilhos da raça Canchim (15 meses, $291 \mathrm{~kg}$ de peso vivo), 13 pertencentes a linhagem antiga, 20 a linhagem nova e 13 provenientes do acasalamento entre estas linhagens. A linhagem antiga é mantida como rebanho fechado desde 1953 e foi formada com base em 53 touros Charoleses importados da França, já a linhagem nova teve origem a partir de $1990 \mathrm{com}$ a utilização de touros Charoleses de diferentes origens (Argentina, Brasil, Estados Unidos, França, Inglaterra), e a partir de 1998, com o acasalamento entre as duas linhagens formou-se a linhagem cruzada. Durante a recria a pasto (165 dias), os animais foram alojados em uma área de pastagem (Panicum maximum cv. Tanzânia), onde o manejo adotado foi o de pastejo rotacionado com lotação variável, para as medidas de desempenho foram executadas pesagens a cada 33 dias, e a mensuração da emissão de metano entérico através da técnica do gás traçador hexafluoreto de enxofre realizada em 12 animais da linhagem antiga e 12 da nova. No período de terminação em confinamento, os animais foram dispostos em 4 baias e receberam alimentação ad libitum durante 105 dias, o ganho de peso foi medido a cada 28 dias e para a mensuração de emissão de metano os mesmos animais avaliados a pasto, tiveram acesso ao sistema automatizado GreenFeed $^{\circledR}$. No momento do abate, foram coletadas informações sobre o peso de carcaça quente, e após 24 horas de resfriamento em câmara fria, o peso da carcaça fria, do traseiro especial, dianteiro e ponta de agulha e na desossa os pesos individuais dos cortes cárneos comerciais. A linhagem nova mostrou-se superior a antiga no período de recria nas variáveis de ganho médio diário, conversão e eficiência alimentar, não se diferenciando dos cruzados. Durante a terminação em confinamento, foi observado o mesmo em relação ao ganho médio diário, já em relação ao consumo, a linhagem nova e os cruzados apresentaram maiores ingestões de alimento comparados à linhagem antiga, enquanto a conversão alimentar dos animais cruzados apresentou maior valor comparados às das linhagens. Na recria a pasto, para se obter maiores ganhos de peso, melhor conversão alimentar e eficiência alimentar, devem ser utilizados animais resultantes de processos de seleção genética. A seleção genética para características de desempenho produtivo não garante 
animais com menores emissões de metano em condições de pastejo. Nos animais em fase de terminação em confinamento, o maior ganho de peso, melhor conversão alimentar e melhor acabamento de carcaça são obtidos através da utilização de animais resultantes de processos de seleção genética. O mesmo tipo de seleção para características de desempenho produtivo em confinamento leva a maiores consumos diários de alimento e consequentemente a maiores emissões de metano diárias.

Palavras-chave: linhagem, recria, seleção genética, terminação 
ABSTRACT

MÉO FILHO, P. Intake, performance, methane emission and carcass traits of Canchim steers recreated on pasture and finished in feedlot. 2017. $57 \mathrm{f}$. Dissertation (Master degree) - Faculty of Animal Science and Food Engineering, University of São Paulo, Pirassununga, 2017.

The objective of this study was to evaluate steers resulting from the genetic selection of different Canchim (5/8 Charolais, 3/8 Zebu) lineages, rearing to pasture and finished in feedlot, in relation to feed intake, performance, enteric methane emission, carcass traits and retail cuts. The experiment was carried out at the Brazilian Agricultural Research Corporation (Embrapa), Southeast Livestock, São Carlos / SP. A total of 46 Canchim steers (15 months, $291 \mathrm{~kg}$ live weight) were used, 13 from the ancient lineage, 20 from the new lineage and 13 from the mating between these lineages. The ancient lineage is kept as a closed herd since 1953 and was formed by 53 Charolais bulls imported from France. The new lineage originated from 1990 with the use of Charolais bulls from different origins (Argentina, Brazil, the United States, France, England), and from 1998 the crossed lineage was formed with the mating between the two lineages. During grazing (165 days), the animals were housed in an pasture area (Panicum maximum cv. Tanzania), where the management used was rotational grazing with variable stocking, for the performance measures were performed weighing every 33 days, and the measurement of the enteric methane emission through the sulfur hexafluoride tracer gas technique was performed in 12 animals of the ancient and 12 of the new lineage. In feedlot the animals were housed in 4 pens and fed ad libitum for 105 days. The weight gain was measured every 28 days and as for the measurement of methane emission the same animals evaluated on pasture had access to the GreenFeed $\AA$ automated system. Information on the hot carcass weight was collected at the time of slaughter and after 24 hours of cooling in the cold chamber, the weights of the cold carcass, of the special hind, fore and spare ribs, and the individual weights of the retail cuts in boning. The new lineage was superior to the ancient one in the rearing period in the variables of average daily gain, conversion and feed efficiency, not differing from the animals crossed. During feedlot, it was observed the same in relation to the average daily gain, already in relation to intake, the new lineage and the crossbreeds presented higher feed intakes compared to the ancient lineage while the feed conversion of the crossed animals presented higher value compared with the new and ancient lineages. In pasture recreating, in order to obtain greater weight gains, better feed conversion and feed efficiency, animals resulting from genetic selection processes must be used. Genetic selection for performance traits does not guarantee animals with lower methane emissions under grazing conditions. For feedlot animals, the highest weight gain, better feed conversion and better carcass finishing are obtained through the use of animals resulting from genetic selection 
processes. The same type of selection for traits of performance in feedlot leads to higher daily feed intake and consequently to higher daily methane emissions.

Key words: lineage, rearing, genetic selection, termination 


\section{LISTA DE FIGURAS}

Figura 1 - Médias mensais de temperatura $(\mathrm{oC})$ e precipitação $(\mathrm{mm})$ para o período experimental (ano 2014-2015) 26

Figura 2 - Área de pastagens ocupada pelos animais durante o período de recria a pasto.

Figura 3 - Evolução das alturas de entrada e saída, ganho de peso, acúmulo de forragem e lotação durante o período de recria a pasto .28

Figura 4 - Animais equipados com os dispositivos de coleta. 30

Figura 5 - Animais visitando os cochos automatizados no período de terminação em confinamento 32

Figura 6 - Animal durante visita ao equipamento GreenFeed ${ }^{\circledR}$ 34

Figura 7 - Carcaças após período de resfriamento de $24 \mathrm{~h}$ 36 


\section{LISTA DE TABELAS}

Tabela 1 - Composição da dieta experimental 33

Tabela 2 - Peso Inicial (PI), peso final (PF), ganho médio diário (GMD), consumo de matéria seca diário (CMSD), conversão alimentar ( $C A)$, eficiência alimentar (EA) de linhagens da raça Canchim recriadas a pasto. 38

Tabela 3 - Fatores de emissão de metano de linhagens de bovinos Canchim recriados a pasto 39

Tabela 4 - Peso Inicial (PI), peso final (PF), ganho médio diário (GMD), ganho por período (GPP), consumo de matéria seca diário (CMSD), conversão alimentar (CA), eficiência alimentar (EA), de linhagens da raça Canchim terminados em confinamento 40

Tabela 5 - Fatores de emissão de $\mathrm{CH} 4$ e $\mathrm{CO} 2$ de linhagens de bovinos Canchim terminados em confinamento

Tabela 6 - Peso de carcaça quente (PCQ), peso de carcaça fria (PCF), Rendimento de carcaça quente $(R C Q)$, rendimento de carcaça fria $(R C F)$, perda por resfriamento (PPR), peso de traseiro (PT), peso de dianteiro (PD), peso da ponta de agulha (PPA), de linhagens de bovinos Canchim.

Tabela 7 - Espessura de gordura subcutânea $(E G)$ e área de olho de lombo $(A O L)$ de linhagens de bovinos da raça Canchim

Tabela 8 - Peso dos cortes cárneos comercias de linhagens de bovinos da raça Canchim recriados a pasto e terminados em confinamento 


\section{LISTA DE SILGLAS}

AA - Amino Ácidos

ABCCAN - Associação Brasileira dos Criados da Raça Canchim

AGCC - Ácidos Graxos de Cadeia Curta

AOL - Área de Olho de Lombo

C - Carbono

CAR - Consumo Alimentar Residual

$\mathrm{CH}_{4}-$ Metano

$\mathrm{CO}_{2}-$ Dióxido de Carbono

$\mathrm{CO}_{2}$-eq. - Dióxido de Carbono Equivalente

EMBRAPA - Empresa Brasileira de Pesquisa Agropecuária

FAO - Food and Agriculture Organization of the United Nations

GEE - Gases de Efeito Estufa

Gt - Giga Tonelada

$\mathrm{H}_{2}-$ Hidrogênio

IPCC - Intergovernmental Panel on Climate Change

LA - Linhagem Antiga

LC - Linhagem Cruzada

LDM - Laser Detector de Metano

LN - Linhagem Nova

MCTI - Ministério da Ciência e Tecnologia

$\mathrm{N}_{2} \mathrm{O}$ - Óxido Nitroso

$\mathrm{O}_{2}-$ Oxigênio

PNMC - Política Nacional sobre a Mudança do Clima

PPM - Parte por Milhão

PPT - Parte por Trilhão

RFID - Sensor de Identificação por Rádio Frequência

$\mathrm{SF}_{6}$ - Hexafluoreto de Enxofre

USDA - United States Department of Agriculture 


\section{SUMÁRIO}

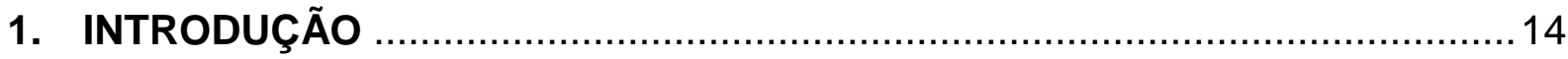

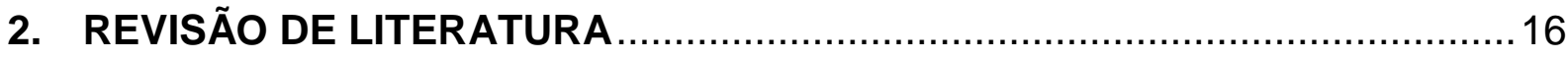

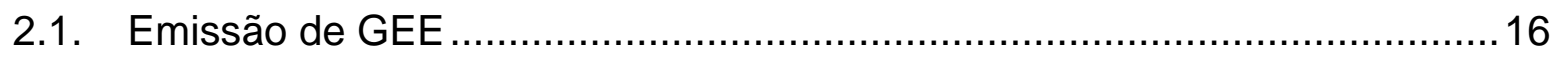

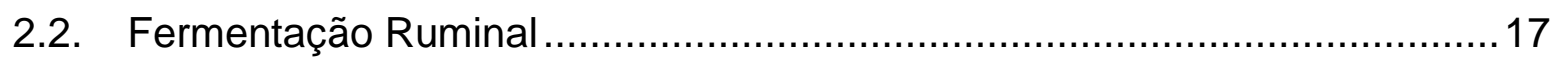

2.3. Estratégias de mitigação para ruminantes .............................................18

2.4. Metodologias para a determinação da emissão de $\mathrm{CH}_{4}$ entérico .................20

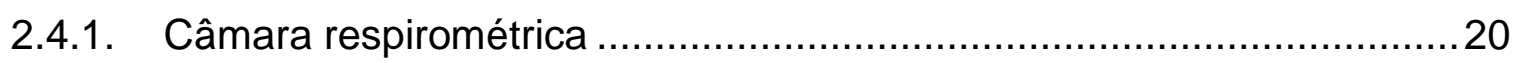

2.4.2. Técnica do gás traçador hexafluoreto de enxofre $\left(\mathrm{SF}_{6}\right)$........................21

2.4.3. Câmara de cabeça para amostragens pontuais $\left(\right.$ GreenFeed $\left.^{\circledR}\right)$.............21

2.4.4. Detector de metano a laser portátil.................................................22

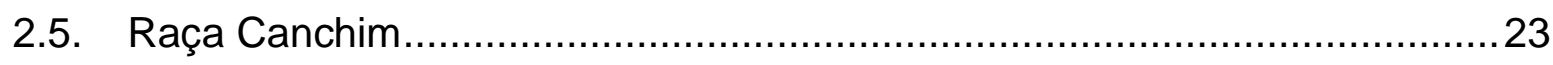

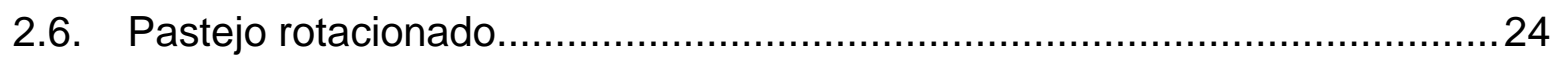

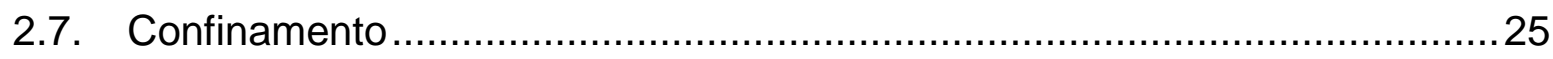

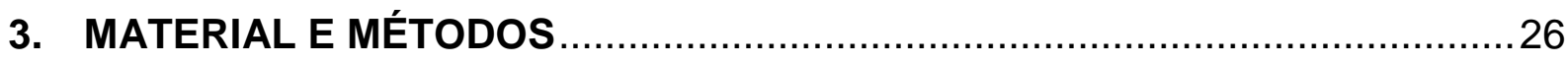

3.1. Local, período e condições meteorológicas ............................................26

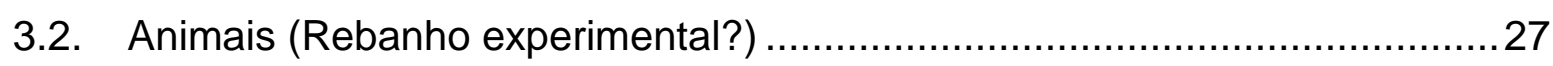

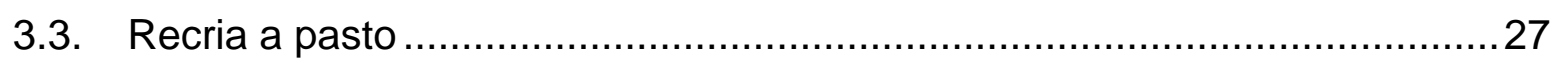

3.3.1. Avaliação da produção de metano entérico no período de recria a

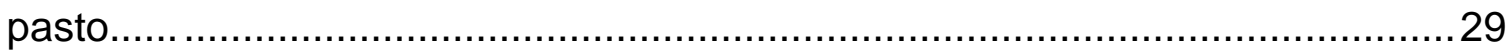

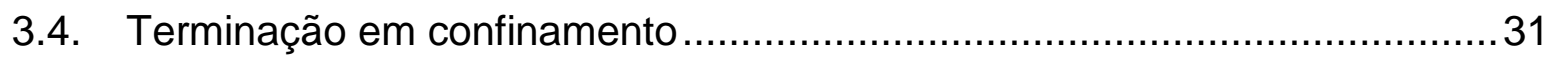

3.4.1. Avaliação da produção de metano entérico durante o período de

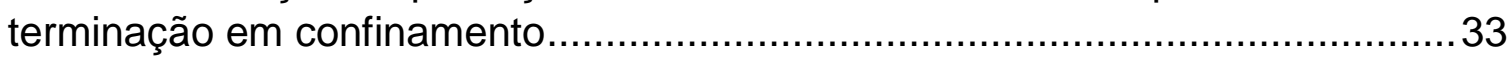

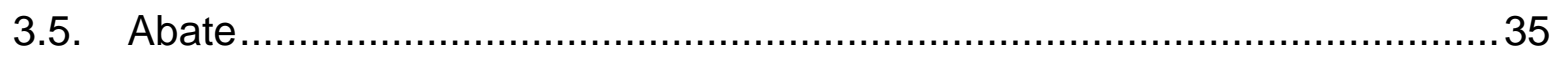

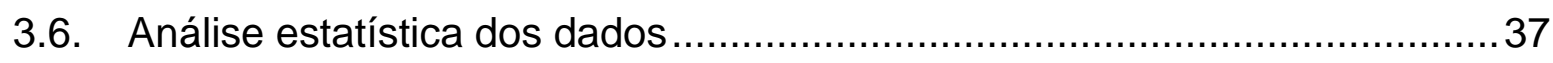

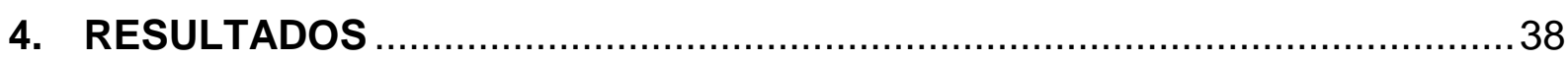

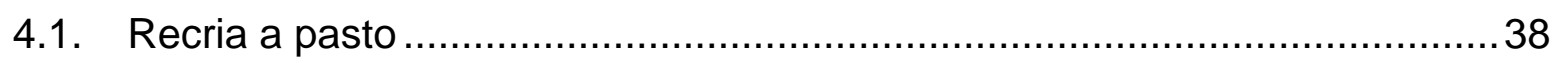

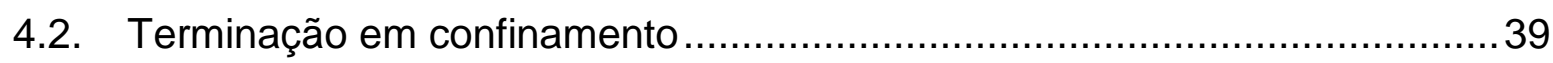

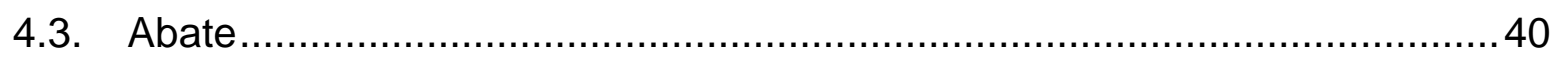

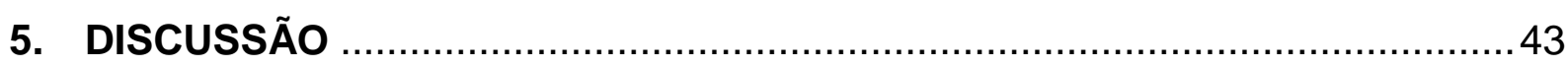

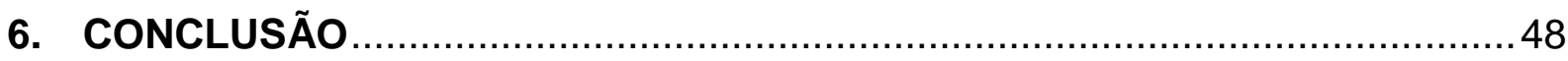

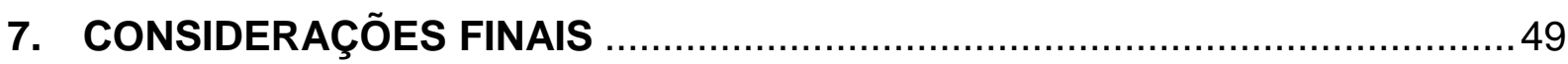

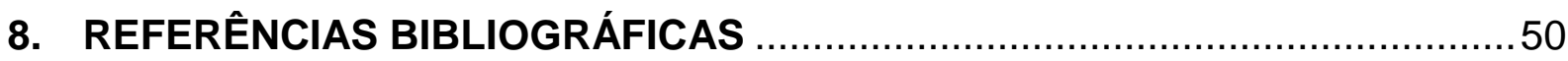




\section{INTRODUÇÃO}

A pecuária e a agricultura são atividades humanas fundamentais à manutenção das sociedades como hoje são conhecidas, pois provêm a população mundial com alimento, vestuário e medicamentos. Interagem com o meio ambiente, em relação à biodiversidade, à conservação do solo e da água, auxiliando também no sequestro de carbono, além de outros. Em 2050, é esperado que a população mundial alcance 9,1 bilhões de pessoas, número 34\% maior do que conhecemos hoje, em razão disto se faz necessário que as atividades agrícolas cresçam em conformidade com a população e ao meio ambiente, de forma a atender de forma sustentável esta crescente demanda (FAO, 2010).

A cadeia produtiva da pecuária do Brasil movimentou $R \$ 483,5$ bilhões em 2015 , crescimento de $27 \%$ sobre o ano anterior (ABIEC, 2016), configurando assim a bovinocultura como um dos principais destaques do agronegócio brasileiro no cenário mundial. O Brasil possui o segundo maior rebanho bovino do mundo, com cerca de 219 milhões de animais (USDA, 2016). Para 2017, é previsto que o país retorne a ser o maior exportador do produto final, a carne, exportando cerca de 1,950 milhões de toneladas de equivalente carcaça o que pode representar cerca de $3 \%$ do total da receita obtida pelo país com exportações neste mesmo ano (USDA, 2016).

O sistema de criação a pasto é predominante no Brasil. Quase que a totalidade dos animais está distribuída em 167 milhões de hectares, uma lotação de cerca de 1,3 cabeças por hectare (ABIEC, 2016). Em relação ao sistema de confinamento em 2015, foram confinados cerca de 5,1 milhões de cabeças, com projeção de queda para 2016. Devido ao aumento no preço do boi magro, à alta nos insumos e à recessão vigente no país, é projetado um total de 4,5 milhões de bovinos confinados para este ano (ABAG, 2016).

De acordo com Oliveira Silva (2016), a produção de animais ruminantes está relacionada as externalidades agrícolas em termos de uso da terra das emissões de gases do efeito estufa (GEE) como o metano $\left(\mathrm{CH}_{4}\right)$ e óxido nitroso $\left(\mathrm{N}_{2} \mathrm{O}\right)$. Estima-se que, em 2010, a agricultura global tenha sido responsável por 5,5 Gt CO2-eq das emissões globais, sendo que desta parcela 2,1 Gt CO $2-e q$ foram provenientes da fermentação entérica de ruminantes (FAOSTAT, 2013). Dependendo da abordagem 
para o cálculo e da abrangência geográfica das emissões, diferentes instituições (IPCC, FAO, EPA entre outros) indicam que a população mundial de bovinos é responsável por cerca de 7 a 18\% das emissões antropogênicas de GEE (FAO, 2013).

Por outro lado, a abordagem setorial indicada pelo IPCC (Intergovernamental Panel on Climate Change) para os inventários de GEE, apesar de adequada, não faz um balanço das opções mitigatórias existentes dentro de cada atividade. Os sistemas de produção de bovinos a pasto, por exemplo, têm significativamente menores emissões ao se contabilizar o dióxido de carbono $\left(\mathrm{CO}_{2}\right)$ atmosférico absorvido pelas gramíneas, promovendo estoque de carbono (C) no solo (SOUSSANA, 2009). Considerando que de toda a superfície terrestre, cerca de 3,7 bilhões de hectares são ocupados por áreas de pastagem permanentes, este potencial de sequestro pode variar entre 0,01 e $0,3 \mathrm{Gt} \mathrm{C} /$ ano (LAL, 2004).

Lobato (2014), ao citar Almeida e Medeiros (2013), aponta como alternativa para mitigação das emissões de GEE, o uso do confinamento estratégico por curto período, durante a fase de terminação dos animais. Se o animal chegar mais cedo ao peso de abate, seu ciclo de vida será menor e consequentemente emitirá menores quantidades de GEE. Diversos autores relataram a variação da emissão de $\mathrm{CH}_{4}$ entérico entre raças e ao longo da vida do animal (HEGARTY et al., 2007; CASSANDRO et al., 2010; CASSANDRO, 2013), fatores estes que justificam buscar a melhoria através da seleção genética. Critérios de seleção poderiam considerar a medida de mitigação potencial, ou seja, a variação individual dentro de cada raça para selecionar animais que emitam menos $\mathrm{CH}_{4}$ por quilo de matéria seca ingerida ou por $\mathrm{kg}$ de carne ou leite produzido (CAVANAGH et al., 2008; VLAMING et al., 2008).

Com base nestes argumentos, este trabalho teve como objetivo, avaliar novilhos resultantes de seleção genética de diferentes linhagens da raça Canchim (5/8 Charolês, $3 / 8$ Zebu) durante as fases de recria a pasto e terminação em confinamento, em relação ao consumo, desempenho, emissão de metano, características de carcaça e cortes cárneos comercias. 


\section{REVISÃO DE LITERATURA}

\subsection{Emissão de GEE}

O efeito estufa é um mecanismo chave na regulação da temperatura da Terra, sem o mesmo não seria possível a vida como hoje é conhecida, já que a temperatura média do nosso planeta não seria de $15^{\circ} \mathrm{C}$, mas de $-6^{\circ} \mathrm{C}$. Este efeito ocorre a partir da energia solar que atinge a superfície terrestre e retorna ao espaço através da reflexão de luz e emissão de calor, uma parte deste fluxo é absorvida pelos gases do efeito estufa (GEE), retendo-o na atmosfera. O dióxido de carbono $\left(\mathrm{CO}_{2}\right)$, metano $\left(\mathrm{CH}_{4}\right)$, óxido nitroso $\left(\mathrm{N}_{2} \mathrm{O}\right)$ e clorofluorcarbonos, são os principais GEE envolvidos neste processo (STEINFELD et al., 2006).

$\mathrm{Na}$ última década, o debate sobre as mudanças climáticas causadas pela emissão destes gases, e consequentemente o aquecimento global, alcançou o setor agropecuário mundial. Em todo o planeta, as nações notaram que a produção de alimento, fundamental para o desenvolvimento das sociedades, também contribui com as emissões de GEE. Em todo o globo, a pecuária é responsável por 8 a 10,8\% destas emissões, sendo que, ao se analisar o ciclo completo (emissões dentro e fora da porteira) a contribuição da pecuária está acima de $18 \%$ das emissões globais (O'MARA, 2011).

A Política Nacional sobre a Mudança do Clima (PNMC) foi instituída no Brasil em 2009 e define o comprometimento do país na adoção de ações mitigatórias, com o objetivo de reduzir as emissões de GEE entre $36,1 \%$ e $38,9 \%$ em relação às emissões projetadas até o ano de 2020, estimadas em 3,24 Gt CO2-eq. Sendo assim a redução a ser alcançada com base no percentual estabelecido seria de 1,214 Gt $\mathrm{CO}_{2}$-eq., até o ano em questão.

Em 2012 no Brasil, do total das emissões nacionais de gases de efeito estufa em CO2-eq, a agropecuária foi responsável por 37\% (446,445 Gg CO2-eq) enquanto a mudança no uso da terra respondeu por $15 \%$ (175,685 Gg CO2-eq) (MCTI, 2014). Tratando-se das emissões relacionadas a agropecuária, a fermentação entérica, processo digestivo normal dos herbívoros ruminantes, correspondeu por aproximadamente $75 \%$ das mesmas, demonstrando a importância de avaliar a emissão de metano entérico em sistemas de produção de ruminantes, já que se trata 
da principal fonte de $\mathrm{CH}_{4}$ de origem antrópica relacionada à agropecuária brasileira (MCTI, 2014).

Entre os anos de 2005 a 2012, as emissões relacionadas à fermentação entérica apresentaram uma variação de 241,2 $\mathrm{Gg} \mathrm{CO}_{2}$-eq. para 249,4 $\mathrm{Gg} \mathrm{CO}_{2}$-eq., um aumento de 3,4\% (MCTI, 2014). Neste mesmo período, a produção de carne bovina passou de 8,6 Mt para 9,3 Mt de equivalente carcaça, apresentando um aumento de 8,1\% (USDA, 2016). Este aumento constante no volume produzido equiparado às emissões, vem sendo alcançado através da intensificação da produção e melhores índices de produtividade, uma vez que as áreas de pastagens vêm se mantendo estáveis em cerca de 160 milhões de hectares, sem a abertura de novas áreas.

\subsection{Fermentação ruminal}

Metano $\left(\mathrm{CH}_{4}\right)$ e gás carbônico $\left(\mathrm{CO}_{2}\right)$ são coprodutos naturais da fermentação microbiana dos carboidratos, e em menor escala dos aminoácidos (AA), dentro do rúmen e intestino grosso dos animais ruminantes. $\mathrm{O} \mathrm{CH}_{4}$ é produzido em condições estritamente anaeróbias por organismos procariontes metanogênicos altamente especializados, pertencentes ao Reino (ou domínio) Archaea e denominados genericamente como arqueias. Nos bovinos, a vasta maioria da produção de $\mathrm{CH}_{4}$ ocorre dentro do reticulo-rúmen, sendo expirado pela boca e narinas durante a eructação, enquanto apenas 2-3\% acabam tendo como destino a emissão retal. A metanogênese ruminal resulta em uma perda de 2 a $12 \%$ da energia bruta ingerida e, dessa forma, ao se reduzir a produção de $\mathrm{CH}_{4}$ melhora-se 0 uso da energia proveniente da alimentação e a eficiência do sistema (JOHNSON; JOHNSON, 1995).

Seguindo este conceito, os principais produtos da fermentação microbiana dos carboidratos são ácidos graxos de cadeia curta (AGCC), $\mathrm{CH}_{4}$ e $\mathrm{CO}_{2}$. A eliminação destes dois últimos é fundamental para o bom funcionamento do metabolismo ruminal, já que o armazenamento de oxigênio dentro do rúmen ocorre na forma de $\mathrm{CO}_{2} \mathrm{e}$ a eliminação do hidrogênio $\left(\mathrm{H}_{2}\right)$ equivalente na forma de $\mathrm{CH}_{4}$. (VAN SOEST, 1994). O metano formado diretamente a partir do $\mathrm{CO}_{2}$ ou através de formato, é o sumidouro de $\mathrm{H}_{2}$ com maior importância para o ruminante. 
Nos processos de síntese dos AGCC acetado e butirato, há a liberação de diferentes quantidades de $\mathrm{H}^{+}$no interior do rúmen, enquanto na síntese do propionato há a o consumo de $\mathrm{H}^{+}$, diminuindo assim a quantidade total de $\mathrm{H}^{+}$disponível para as arqueias reduzirem $\mathrm{CO}_{2}$ para $\mathrm{CH}_{4}$. Este mesmo AGCC pode ser formado por duas vias diferentes, succinato e acrilato, envolvendo diferentes bactérias, sendo que a via succinato é considerada de importância primordial no rúmen (RUSSELL; WALLACE, 1997).

Recentemente, foi descrito um novo grupo de metanogênicas metilotróficas que não requer o hidrogênio como uma fonte de energia, o mesmo parece desempenhar um papel na formação do $\mathrm{CH}_{4}$ em ruminantes (POULSEN et al., 2012). O papel relativo destas arqueias nas emissões de $\mathrm{CH}_{4}$ ainda não foi confirmado, mas esta é uma exploração importante, que pode explicar a falta de relação observada entre a redução da produção de metano e a abundância de metanogênicas hidrogeniotróficas tradicionais (KARNATI et al., 2009; TEKIPPE et al., 2011). No entanto, a importância relativa das vias de acrilato na formação do propionato pode aumentar em dietas de alto teor de concentrado. Valerato, um AGCC de menor síntese, também é resultante do metabolismo dos carboidratos, e da mesma forma age como sumidouro líquido para redução de equivalentes de $\mathrm{H}^{+}$(RUSSELL; WALLACE, 1997), mas devido a sua pequena atividade, essa via só resulta em um pequeno declínio na produção de $\mathrm{H}^{+}$.

Os outros dois AGCC produzidos em menor quantidade dentro do rúmen, isobutirato e isovalerato, originam-se a partir do metabolismo de aminoácidos de cadeia ramificada (valina e leucina, respectivamente), resultando na formação de $\mathrm{CO}_{2}$ e amônia $\left(\mathrm{NH}_{3}\right)$ (VAN SOEST, 1994).

\subsection{Estratégias de mitigação para ruminantes}

Tratando-se de estratégias de mitigação de GEE provenientes de fermentação entérica, pode-se listar três principais categorias: melhorias nas práticas de alimentação, uso de agentes específicos e aditivos na dieta, além do melhoramento genético. A gestão intensiva das pastagens, uso de grãos, alimentos concentrados e leguminosas, processamento de forragens de modo a aumentar sua digestibilidade, e específica adição de taninos, saponinas, óleos essenciais, ionóforos, compostos de 
nitrato, leveduras, malato e fumarato são estratégias que podem reduzir as emissões de $\mathrm{CH}_{4}$ por unidade de produto (GRAINGER; BEAUCHEMIN, 2011).

De modo semelhante, a intensificação da produção animal, a melhoria do sistema de produção, tem como objetivo a melhoria da eficiência do sistema, levando em consideração as características funcionais que podem reduzir o desperdício dentro do mesmo (energia, combustível, fertilizantes, taxa de prenhes, mortalidade), e dessa forma as emissões de gases do efeito estufa.

O melhoramento genético é uma ferramenta que pode ser utilizada com objetivo de reduzir as emissões de $\mathrm{CH}_{4}$ de três maneiras: selecionando animais para maior ganho de peso e melhor eficiência alimentar, interferindo positivamente na intensificação da produção animal e na melhoria da eficiência do sistema de produção; e na redução direta da emissão de GEE, por meio do cruzamento de animais preditos para alta ou baixa emissão de gases do efeito estufa (CASSANDRO, 2013).

Através de cruzamentos que possam melhorar a eficiência dos animais buscase a intensificação da produção animal, conduzindo a uma redução do número total de cabeças necessárias para atender um determinado nível de produção. Uma queda de até $8 \%$ nas emissões é estimada através da redução do número de animais menos eficientes (JARDINE et al., 2012).

Uma das formas de classificar a eficiência alimentar é o consumo alimentar residual (CAR). Esta medida busca comparar a ingestão prevista do animal com base no seu peso vivo médio durante o período de avaliação e sua velocidade de ganho de peso com a ingestão de alimentos observada (ARCHER et al., 1999). Estudos com o objetivo de selecionar bovinos de corte com CAR reduzido concluíram que a performance de crescimento não foi comprometida e o menor consumo de ração resultou em menor produção de $\mathrm{CH}_{4}$ (NKRUMAH et al., 2006; HEGARTY et al., 2007). A inclusão do CAR em programas de melhoramento genético de bovinos corte pode levar a uma redução anual de 3,1\% nas emissões de $\mathrm{CH}_{4}$ (VEERKAMP, 2002).

A redução direta nas emissões de GEE através de animais já definidos como grandes ou pequenos emissores de $\mathrm{CH}_{4}$, pode ser obtida já que, recentemente foi determinado que a genética do animal desempenha papel importante na determinação da composição da microflora do rúmen e intestino. Essa forma a partir 
do momento que houver um número substancial de animais medidos individualmente quanto suas emissões, será possível a seleção de animais que apresentem um maior potencial de mitigação de GEE (CASSANDRO, 2013).

\subsection{Metodologias para a determinação da emissão de $\mathrm{CH} 4$ entérico}

Métodos de pesquisa utilizados para estudar as emissões de $\mathrm{CH}_{4}$ entérico e as práticas de mitigação possuem elementos em comum, porém diferem em termos de aparatos e abordagens utilizadas. A medida precisa das emissões provenientes dos ruminantes é necessária para publicação de inventários nacionais, criação e avaliação das estratégias de mitigação, e desenvolvimento de protocolos para seleção genética. Existem diversas tecnologias utilizadas em todo o mundo para quantificar a emissão de metano entérico. Estas diferem em seu modo de aplicação, custo, acurácia e precisão, mas todos os métodos diretos se baseiam em mensurar a concentração de $\mathrm{CH}_{4}$ no ar (HAMMOND et al., 2016). Dentre elas podemos citar:

- Câmara respirométrica.

- Técnica do gás traçador hexafluoreto de enxofre (SF6).

- Câmara de cabeça para a amostragens pontuais (GreenFeed $\left.{ }^{\circledR}\right)$.

- Detector de metano a laser portátil.

\subsubsection{Câmara respirométrica}

Câmaras respirométricas têm sido utilizadas como calorímetros indiretos para a mensuração das trocas respiratórias e as perdas de energia na forma de $\mathrm{CH}_{4}$ de ruminantes por mais de 120 anos (ARMSBY, 1903; KELLNER, 1913), sendo que, atualmente seu principal foco de uso dentro da pesquisa é medir as emissões de $\mathrm{CH}_{4}$ entérico. O princípio deste sistema é que o ar recolhido do ambiente para o interior da câmara circula em seu interior e em torno do animal, homogeneizando-se ao $\mathrm{CH}_{4}$ emitido, durante este processo ocorre a amostragem do ar de entrada e o de saída. A produção de metano é determinada multiplicando-se o fluxo de ar através do sistema pela diferença entre a concentração do ar entrada e o de saída (HAMMOND et al., 2016). 


\subsubsection{Técnica do gás traçador hexafluoreto de enxofre $\left(\mathrm{SF}_{6}\right)$}

A técnica do gás traçador $\mathrm{SF}_{6}$ foi desenvolvida e patenteada por Zimmerman (1993) e seu primeiro uso relatado para a estimativa da emissão de $\mathrm{CH}_{4}$ de ruminantes foi feito por Johnson et al. (1995). No Brasil, a técnica foi adaptada por Primavesi et al. (2002) e aprimorada por Berndt et al. (2014). Esta técnica é adequada tanto para animais confinados, bem como livres em pastejo e baseia-se no uso de um tubo de permeação ou cápsula, que é ministrado pela boca do animal e permanece no rúmen/retículo liberando uma pequena e conhecida taxa do gás traçador. $\mathrm{O} \mathrm{SF}_{6}$ liberado pela cápsula mistura-se aos gases da fermentação ruminal atuando como um traçador do gás metano produzido e eructado pelo animal.

O ar expirado pela narina e boca do animal é continuamente coletado por meio de um tubo com cerca de $3 \mathrm{~mm}$ de diâmetro, equipado com limitador de fluxo para regular a taxa de amostragem. Este tubo é afixado a um cabresto e conectado a um recipiente de armazenamento pré-evacuado (canga). O intervalo de amostragem recomendando é de $24 \mathrm{~h}$, ao longo de um período mínimo de cinco dias consecutivos, além de amostras de ar do ambiente (brancos), os animais presentes nos diferentes tratamentos devem ser amostrados ao mesmo tempo.

A emissão de $\mathrm{CH}_{4}$ diária é calculada através da relação $\mathrm{CH}_{4}: \mathrm{SF}_{6}$ presente na canga, corrigida pela concentração dos mesmo nos brancos, em conjunto com a taxa de permeação pré-determinada da cápsula de SF6.

\subsubsection{Câmara de cabeça para amostragens pontuais (GreenFeed ${ }^{\circledR}$ )}

Câmaras respirométricas e a técnica do $\mathrm{SF}_{6}$ são normalmente utilizados para se obter medidas da emissão de $\mathrm{CH}_{4}$ de um número limitado de animais pelo período de 24 h. Porém, existe uma demanda cada vez maior em determinar a emissão de forma precisa, de um grande número de animais a curto prazo (durante a alimentação e a ordenha por exemplo). Medidas repetidas a curto prazo, utilizando máscaras, vêm sendo utilizadas (WASHBURN; BRODY, 1937) para se obter estimativas das taxas diárias das trocas respiratórias e emissão de $\mathrm{CH}_{4}$.

O sistema GreenFeed ${ }^{\circledR}$ (C-Lock Inc., Rapid City, South Dakota, USA) é um dispositivo estático de medição a curto prazo, que mede individualmente a emissão de $\mathrm{CH}_{4}$ e $\mathrm{CO}_{2}$ de bovinos, através da integração das medidas de fluxo de ar, 
concentração de gás e detecção da posição da cabeça durante a visita de cada animal ao equipamento (ZIMMERMAN; ZIMMERMAN, 2012). A medida das emissões ocorre através da combinação de um exaustor e sensor que induz o fluxo de ar passando pela cabeça do animal, permitindo que o ar expirado seja recolhido e amostrado. $O$ ar recolhido é homogeneizado, filtrado e a taxa de fluxo de ar é medida por meio de um anemômetro. A concentração de $\mathrm{CH}_{4}, \mathrm{CO}_{2}$ e $\mathrm{O}_{2}$ presente nas amostras é medida através de um analisador de espectro infravermelho não dispersivo.

Os animais têm liberdade de visitar o equipamento a qualquer momento, porém a amostragem dos gases só acontece após certo período entre visitas o que é determinado pela programação pré-estabelecida no sistema. As medidas da emissão de $\mathrm{CH}_{4}$ através de uma unidade $\mathrm{GreenFeed}^{\circledR}$ são normalmente realizadas ao longo de períodos curtos (5 min), distribuídos durante dias/semanas/meses e dependendo da visita voluntária do animal. Para distribuir as medidas ao longo do dia, o software de controle permite ao pesquisador o controle do tempo e da oferta de alimento. Este equipamento pode ser utilizado em uma variedade de sistemas, inclusive a pasto. Hristov et al. (2015) fazem uma explanação detalhada do funcionamento e utilização do equipamento.

\subsubsection{Detector de metano a laser portátil}

Outra tecnologia que pode monitorar a concentração de $\mathrm{CH}_{4}$ do ar expirado pelos animais é o laser detector de metano (LDM) (RICCl et al., 2014). As medidas da concentração de $\mathrm{CH}_{4}$ são tomadas manualmente por meio de um aparelho portátil na distância de 1-3 metros a partir do animal, e são baseadas em espectroscopia de absorção do infravermelho para o $\mathrm{CH}_{4}$. A coleta dos dados por meio do aparelho ocorre continuamente por curtos períodos de tempo (2-4 min), os dados resultantes consistem de uma série de picos que representam o ciclo respiratório do animal, apenas os picos que refletem a expiração ou eructação do animal são considerados durante a análise e são ajustados de acordo com a distância e medidas do ambiente também obtidas através do LDM (RICCI et al., 2014). 


\subsection{Raça Canchim}

Aproveitar os efeitos benéficos da heterose residual nas populações compostas é a principal razão para a formação das mesmas. O uso de raças zebuínas em cruzamentos com raças taurinas vem sendo empregado crescentemente na cadeia produtiva da carne nos trópicos (ex.: Santa Gertrudes, Beefmaster, Jamaica Hope, etc.), com o objetivo de consorciar a rusticidade e adaptabilidade do Zebu com a precocidade e qualidade da carne de raças taurinas (POTT; PAINO; ALENCAR, 1997). O cruzamento entre raças é um método efetivo de melhoramento, que gera efeitos a curto prazo, muito empregado para: aumentar a produtividade devido ao vigor híbrido (heterose); formar rebanhos comerciais com a combinação desejável de características não disponíveis em qualquer uma das raças; e desenvolver novas raças (POTT; PAINO; ALENCAR, 1997).

De acordo com Alencar e Barbosa (2003), durante o desenvolvimento da população composta é necessário que haja escolha criteriosa das raças formadoras e da porcentagem de cada raça na população, e também, que a base genética seja a mais ampla possível, para evitar a ocorrência de acasalamentos endogâmicos no decorrer das gerações, além de que um programa de melhoramento genético (seleção e sistema de acasalamento) bem delineado seja implantado.

A raça bovina Canchim (bimestiço composto de 5/8 Charolês e 3/8 Zebu) foi desenvolvida pelo Ministério da Agricultura na então Estação Experimental de São Carlos (atualmente Embrapa Pecuária Sudeste), a partir da década de 1940, por meio do cruzamento alternado entre Charolês e Zebu (Guzerá, Indubrasil e Nelore). O objetivo geral estabelecido foi aproveitar os efeitos favoráveis da heterose (vigor híbrido), complementar as características desejáveis do Charolês (alta velocidade de crescimento e boa qualidade de carne) e do Zebu (adaptação aos trópicos) e facilitar a introdução de genes do Charolês nos sistemas de produção de carne bovina do Brasil por meio do uso da raça Canchim (ABCCAN, 2016).

A linhagem Antiga, mantida na Embrapa Pecuária Sudeste desde 1953 como rebanho fechado, foi formada com base em 53 touros Charolês importados e filhos de touros importados da França em diferentes ocasiões (1922, 1938, 1948 e 1962). No início, os criadores formadores de Canchim utilizaram intensa e quase que exclusivamente, com poucas exceções, reprodutores Charolês, 5/8 Charolês $+3 / 8$ 
Zebu e Canchim oriundos do rebanho da atual Embrapa Pecuária Sudeste (ALENCAR, 2000).

Quanto ao Zebu, a diferença foi a utilização de fêmeas da raça Nelore e aneloradas para cruzamento com touros Charolês nos rebanhos de criadores particulares, enquanto o rebanho da Embrapa Pecuária Sudeste foi formado com base no uso de touros e matrizes das raças Guzerá e Indubrasil, com pequena participação de fêmeas Nelore. Em consequência, a base genética da raça ficou limitada a esses recursos até o começo da década de 1990, quando a partir da aprovação pelo Ministério da Agricultura, Pecuária e Abastecimento do processo de formação de novas linhagens, por solicitação da Associação Brasileira de Criadores de Canchim, a base genética da raça vem sendo ampliada desde este ano com a utilização de touros Charolês de diferentes origens (Argentina, Brasil, Estados Unidos, França, Inglaterra), incluindo a introdução do caráter mocho na população, mas não se conhecem ainda, em termos técnico-científicos, quais as vantagens/desvantagens do uso de animais dessa nova linhagem, principalmente quanto às características de tolerância aos ectoparasitas (carrapatos), aspectos reprodutivos e acabamento de carcaça (ALENCAR, 2000).

Animais provenientes do cruzamento entre as linhagens Nova e Antiga começaram a ser concebidos a partir do ano de 1998 e desde 2012 na Embrapa Pecuária Sudeste são estudados animais das diferentes linhagens, buscando manter a linhagem Antiga como rebanho fechado e compará-la com as linhagens Nova e a Cruzada. Os animais reprodutores são acasalados com base nas DEP's (Diferenças Esperadas na Progênie) disponibilizadas pelo Geneplus-Embrapa, referentes às características de seleção tradicionais: peso ao nascimento, perímetro escrotal, escores de pelagem, umbigo e conformação frigorífica, peso à desmama, peso ao sobreano e idade ao primeiro parto. Nesta nova etapa, a Embrapa Pecuária Sudeste estuda, por meio do projeto ADAPT+ (02.12.02.008.00.00) critérios não convencionais, para disponibilizar, futuramente, animais tolerantes ao calor, com boa resistência aos parasitas, precoces, e com melhor acabamento de carcaça.

\subsection{Pastejo rotacionado}

Sistemas de produção em pastagens bem manejadas possuem uma maior capacidade de sequestro de carbono no solo do que culturas agrícolas, principalmente 
devido à capacidade fotossintética das plantas forrageiras em converter $\mathrm{CO}_{2} \mathrm{em}$ massa de folhas, colmos e raízes. Fatores de erro de manejo, como a altura de pastejo pode alterar o ganho médio diário e ganho de peso por hectare (DA SILVA et al., 2013). De acordo com o modelo proposto por Mott (1960), a baixa taxa de lotação tem como resultado uma alta altura de pastejo, alta oferta de forragem, alta ingestão de matéria seca e alto ganho médio diário, em contrapartida promove baixo ganho por hectare. As pastagens com alta taxa de lotação, permitem um maior ganho por hectare, apesar da baixa altura de pastejo, baixa ingestão de matéria seca e baixo ganho médio diário.

A exploração das pastagens de forma extensiva, reduz a produção de forragem, o teor de matéria orgânica do solo e consequentemente o sequestro de carbono. Além disso, como a massa de forragem torna-se limitada, o consumo de alimento com baixa digestibilidade aumenta, o que pode significar maiores emissões de $\mathrm{CH}_{4}$ entérico. Quando se é adotado o regime de pastejo rotacionado, há um consumo mais homogêneo da forragem, dessa forma a mesma se mantém em estado vegetativo por mais tempo, o que resulta em um maior sequestro de $\mathrm{CO}_{2}$, maior digestibilidade e disponibilidade de nutrientes para os animais e consequentemente uma menor emissão de $\mathrm{CH}_{4}$ por kg de forragem consumida (RUSSELL, 2016).

\subsection{Confinamento}

A redução da idade ao abate e do número de dias que os animais permanecem em confinamento pode ter um impacto significativo na redução das emissões de GEE ligadas a sistemas de produção animal (HRISTOV, 2013). Estimativas anteriores da eficiência dos sistemas da criação de bovinos no Brasil indicam que a redução da idade ao abate através da gestão adequada das pastagens e do confinamento estratégico para terminação por 90 dias pode reduzir significativamente as intensidades de emissão, mesmo ao considerar todas as emissões relacionadas à produção e distribuição de insumos. Estas estimativas ilustram claramente o potencial de reduzir as emissões de $\mathrm{CH}_{4}$ por unidade de produto (kg de carne), quando os sistemas de produção de carne bovina são intensificados especialmente para terminação (BERNDT; TOMKINS, 2013). 


\section{MATERIAL E MÉTODOS}

\subsection{Local, período e condições meteorológicas}

O experimento foi desenvolvido na Unidade Descentralizada da Empresa Brasileira de Pesquisa Agropecuária - EMBRAPA, unidade Pecuária Sudeste, localizada no município de São Carlos, Estado de São Paulo, distante $8 \mathrm{~km}$ do centro da cidade e 234 km da Capital do Estado, a 21 57' 33.32" S 47 50' 33.28" W, à altitude de $856 \mathrm{~m}$. O projeto foi avaliado pelo Comitê Local de Ética em Experimentação Animal - CEUA (Embrapa - Pecuária Sudeste) e recebeu parecer favorável registrado com protocolo número: 03/2014. O clima é do tipo Cw, na classificação de Koeppen, ou seja, subtropical com inverno seco e verão quente e úmido. O período de execução foi de dezembro de 2014 a setembro de 2015. As médias de temperatura e precipitação durante o período experimental são apresentadas na Figura 1.

Figura 1 - Médias mensais de temperatura $\left({ }^{\circ} \mathrm{C}\right)$ e precipitação $(\mathrm{mm})$ para o período experimental

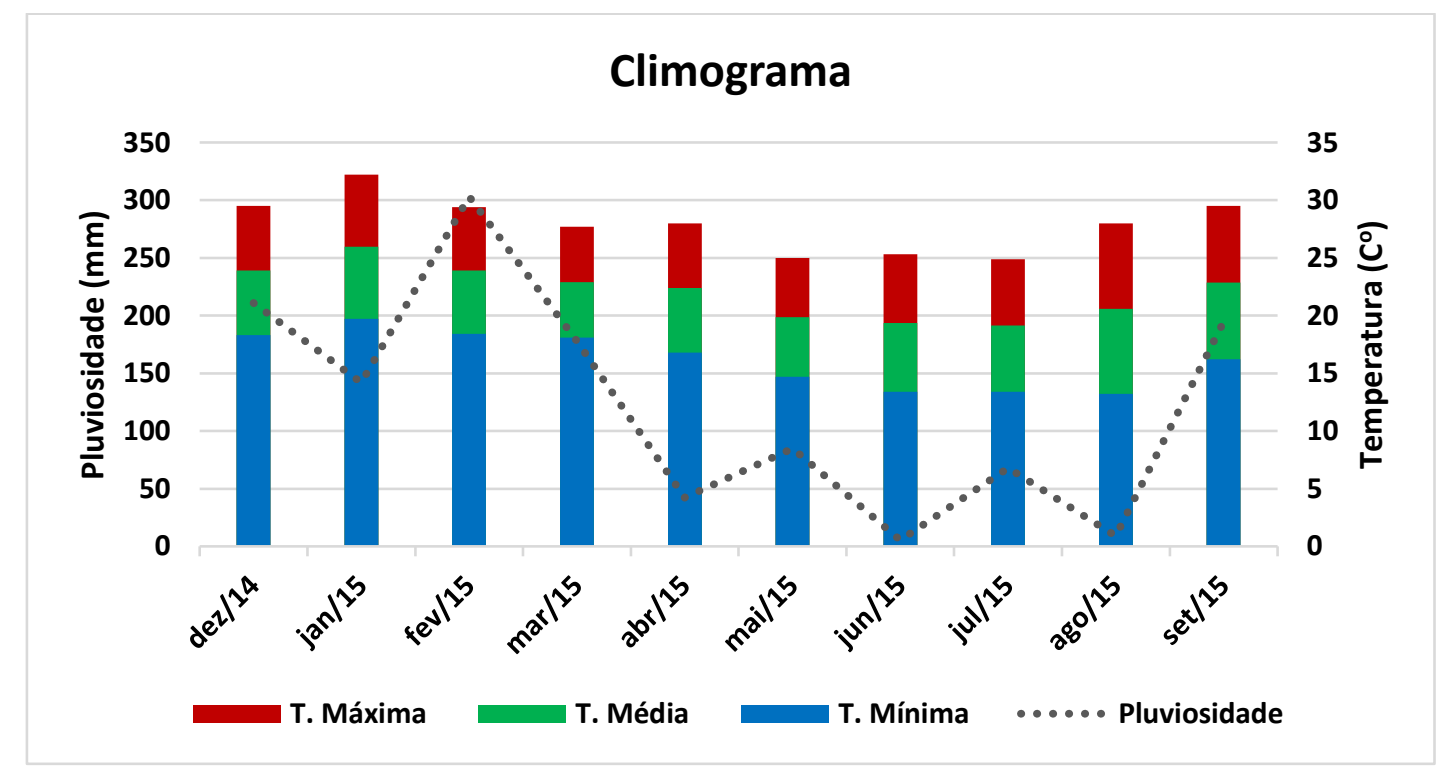

Fonte: Estação Meteorológica Embrapa Pecuária Sudeste. 


\subsection{Animais}

Foram utilizados 46 novilhos castrados da raça Canchim com peso inicial 280 $\pm 32 \mathrm{~kg}$ e $15 \pm 3$ meses de idade. Pertencentes a três linhagens distintas: Antiga, Nova e Cruzada (esta resultante do acasalamento dos animais das linhagens Nova e Antiga). Os animais foram criados na própria Embrapa Pecuária Sudeste, oriundos do rebanho experimental de animais da raça Canchim, nascidos entre agosto e novembro de 2013.

\subsection{Recria a pasto}

Durante o período de recria a pasto, que teve duração de 165 dias (dezembro/2014 - junho/2015), os 46 animais foram distribuídos de acordo com suas linhagens e peso, em uma área de pastagem, composta de 4 módulos com 12 piquetes cada (Figura 2), providos de bebedouro e cocho para suplementação mineral, onde o método de pastejo adotado foi o rotacionado com lotação variável. A espécie forrageira que compunha o sistema era Panicum maximum cv. Tanzânia e recebeu adubação nitrogenada durante a época das águas, na saída dos animais de cada piquete, totalizando $400 \mathrm{~kg}$ de N/ha/ano.

Figura 2 - Área de pastagens ocupada pelos animais durante o período de recria a pasto

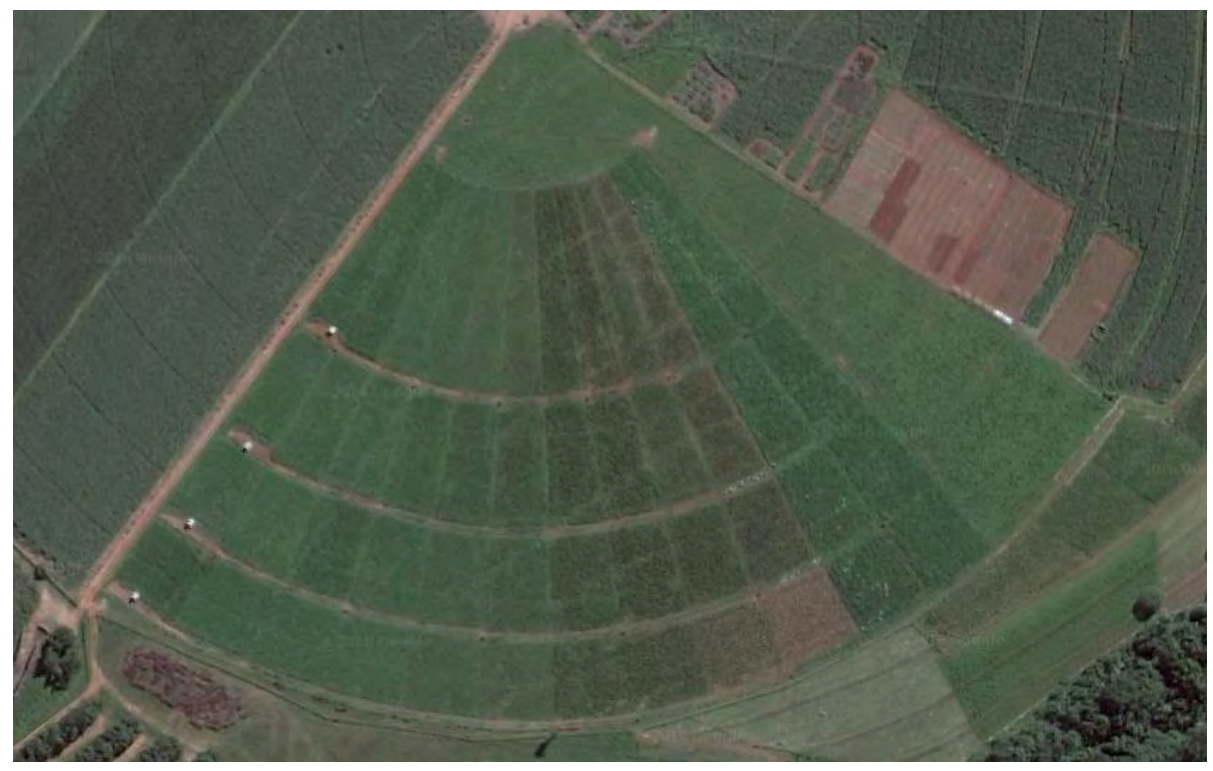

Fonte: Google Maps (2016) (acesso em: 14/12/2016) 
O período de pastejo adotado foi de três dias por piquete e o de descanso de 33 dias, totalizando 36 dias por ciclo. A lotação animal foi ajustada seguindo a técnica de put-and-take (MOTT; LUCAS, 1952), de forma a garantir oferta semelhante entre os módulos. Para o acompanhamento do ganho de peso foram realizadas pesagens com jejum prévio no início e no final do experimento e neste intervalo a cada 36 dias, sem jejum. Foram observados 5 ciclos de pastejo. Para quantificar a produção de massa de foragem, foram realizadas coletas nos piquetes 4 e 10 de cada módulo antes da entrada e após a saída dos animais (pré/pós-pastejo) no decorrer de cada ciclo de pastejo. A amostragem foi realizada de forma direta por meio do método do quadrado, onde a moldura possuía dimensão de 2,25 $\mathrm{m}^{2}(1,5 \times 1,5 \mathrm{~m})$, e escolha aleatória dos pontos de coleta. O material coletado acima do resíduo foi pesado, e uma sub-amostra retirada para determinação da matéria seca, realizada em estufa a 65ํㅡ pelo período de $72 \mathrm{~h}$. Na figura 3, são apresentadas as evoluções das alturas de entrada e saída dos piquetes, ganho de peso, acúmulo de forragem e lotação durante o período de recria a pasto.

Figura 3 - Evolução das alturas de entrada e saída, ganho de peso, acúmulo de forragem e lotação durante o período de recria a pasto

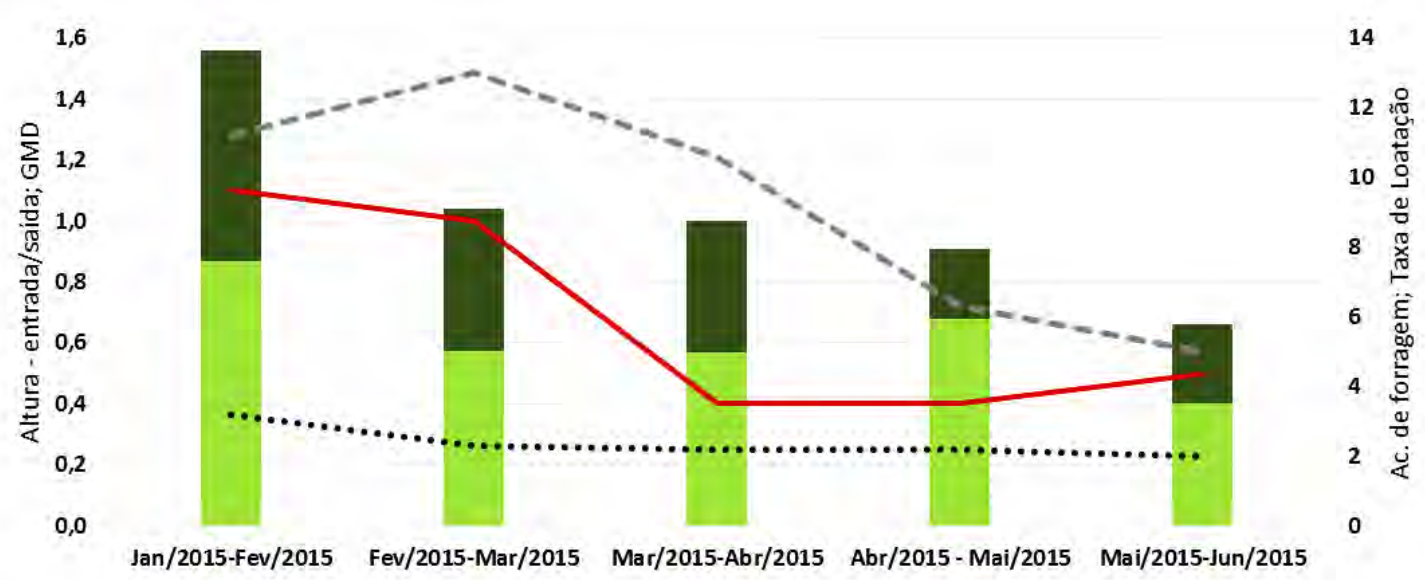

W entrada $(\mathrm{m})=\mathrm{h}$ sáida $(\mathrm{m}) \longrightarrow \mathrm{GMD}(\mathrm{kg} / \mathrm{d}) \cdots \cdots$ Ac. de forragem (T MS/há) $=--$ Taxa de lotação (UA/há) 
O consumo de matéria seca (CMS) foi estimado com uso das estimativas de peso vivo médio (PVM) e ganho médio diário (GMD) através da equação proposta por Azevêdo (2010):

$$
\mathrm{CMS}=-2,6098+0,08844 \mathrm{PVM}^{0,75}+4,4672 \mathrm{GMD}-1,3579 \mathrm{GMD}^{2}
$$

Com base nas medidas de peso dos animais e consumo de matéria seca, foram calculados o ganho médio diário (GMD), a conversão (CA) e a eficiência (EA).

\subsubsection{Avaliação da produção de metano entérico no período de recria a pasto}

A emissão de metano foi mensurada através da técnica do gás traçador $\mathrm{SF}_{6}$ (JOHNSON et al. 1994, adaptada por PRIMAVESI et al., 2002 e aprimorada por BERNDT et al., 2014) onde cada um dos 24 animais (12 da linhagem antiga e 12 da linhagem nova) foram avaliados diariamente durante 24 horas por 5 dias consecutivos, em abril de 2015. Os animais da linhagem cruzada não foram avaliados, pois a técnica do $\mathrm{SF}_{6}$ é uma técnica onerosa e trabalhosa, por isso, neste trabalho foi objetivado quantificar apenas a emissão das linhagens originais. Os novilhos foram equipados com cabrestos e cangas (Figura 3) para coleta de gases 15 dias antes da amostragem, de forma a permitir que os animais se adaptassem aos aparatos facilitando o manejo no período de amostragem. A taxa de liberação ( $T L)$ do gás a partir dos tubos de permeação de $\mathrm{SF}_{6}$ foi determinada por método gravimétrico, mantendo os tubos em estufa a $39^{\circ} \mathrm{C}$, através de pesagens semanais antes de sua inserção no rúmen. Os tubos preenchidos com SF 6 e TL conhecidas (1431 $\pm 59 \mathrm{ng} / \mathrm{min}$ ) foram administrados oralmente a cada um dos 24 animais 15 dias antes da amostragem, de forma a permitir que o fluxo do gás traçador se estabilizasse no rúmen.

Os animais foram equipados com cabrestos para coleta de gás ligados a cangas de PVC pré-evacuadas, confeccionadas para permitir $50 \%$ de enchimento em $24 \mathrm{~h}$. As coletas tiveram início às 7:00 h, diariamente os animais foram recolhidos de seus piquetes ao centro de manejo de forma a facilitar a troca dos equipamentos. As pressões das cangas foram mensuradas imediatamente após completadas as $24 \mathrm{~h}$ de coleta para avaliação da qualidade da coleta. Se a pressão final fosse maior do que a esperada poderia significar que o cabresto foi bloqueado ou desconectado, enquanto abaixo do esperado que o sistema estava com algum ponto de vazamento, em 
qualquer situação foi realizada a troca do cabresto e da canga. Realizada a troca dos recipientes de coleta, os animais eram reconduzidos aos seus piquetes de origem.

Figura 4 - Animais equipados com os dispositivos de coleta (Cabresto e Canga)

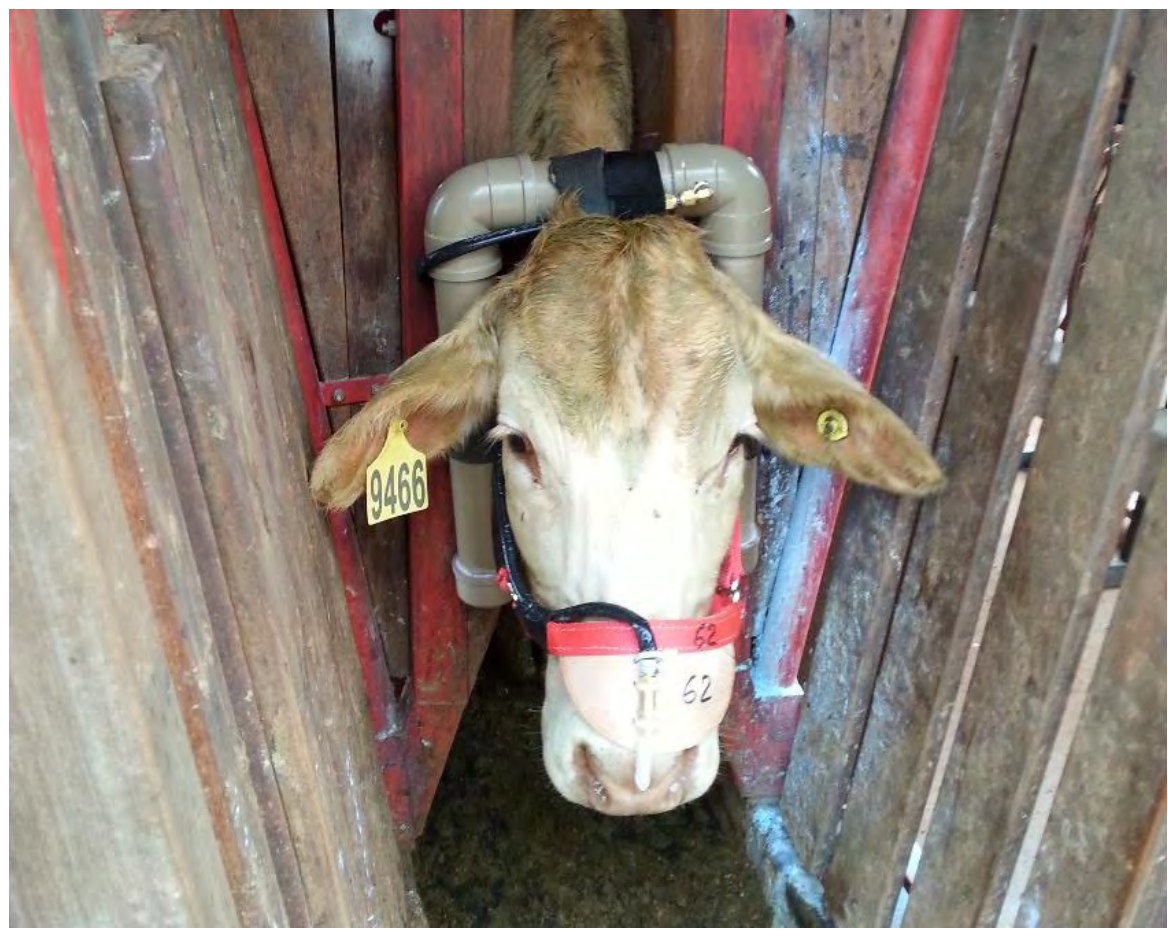

Fonte: Própria autoria.

Foram também coletadas amostras para determinação da concentração de $\mathrm{SF}_{6}$ e $\mathrm{CH}_{4}$ no ambiente. As pressões, datas e horários da retirada dos recipientes em ambos os casos eram anotados para controle. No momento da análise por cromatografia, as cangas foram pressurizadas com $\mathrm{N}_{2}$ até aproximadamente $10 \%$ acima da pressão atmosférica, sendo a mesma realizada em cromatógrafo Shimadzu modelo GC-2014 (Shimadzu Corporation, Japan), seguindo o método descrito por Johnson et. al. (1995). As curvas de calibração foram estabelecidas utilizando gás padrão certificado pela empresa "White Martins" com as concentrações de $\mathrm{CH}_{4}$, em ppm (4,85 $\pm 5 \%, 9,96 \pm 1,65 \%$ e 19,1\% $\pm 3,44 \%)$, e SF 6 , em ppt (34 $\pm 9,0,91,0 \pm 9,0$ e 978,0 $\pm 98,0$ ), de acordo com Westberg et. al. (1998).

As emissões de $\mathrm{CH}_{4}$ foram calculadas através da proporção de $\mathrm{CH}_{4}: \mathrm{SF}_{6}$ na canga, com cada um dos gases corrigidos para a concentração do branco, em conjunto com a taxa de permeação pré-determinada das cápsulas de SF6. Na seguinte 
equação, onde está subscrito $M$ indica amostra medida do animal, e o subscrito $B G$ indica a concentração do branco:

$$
\mathrm{RCH}_{4}=\mathrm{RSF}_{6} \times \frac{(\mathrm{CH} 4)_{\mathrm{M}}-(\mathrm{CH} 4)_{\mathrm{BG}}}{(\mathrm{SF} 6)_{\mathrm{M}}-(\mathrm{SF} 6)_{\mathrm{BG}}} \times\left(\frac{\mathrm{MW}_{\mathrm{CH} 4}}{\mathrm{MW}_{\mathrm{SF} 6}}\right) \times 1000
$$

e, ainda, $\mathrm{RCH}_{4}\left(\mathrm{~g} / \mathrm{d}\right.$ ) é a taxa de emissão de $\mathrm{CH}_{4}$ ruminal calculada em $\mathrm{g} / \mathrm{d}$; $\mathrm{RSF} 6$ representa a taxa de liberação medida a partir da cápsula de $\mathrm{SF}_{6}(\mathrm{mg} / \mathrm{d}) ; \mathrm{MW}_{\mathrm{CH} 4}$ é a massa molecular do $\mathrm{CH}_{4}$ (16), e MWSF6 é a massa molecular do $\mathrm{SF}_{6}$ (146). As concentrações de $\mathrm{CH}_{4}$ são expressas em ppm e as de $\mathrm{SF}_{6}$ em ppt. $O$ fator 1000 realiza a conversão da unidade para que $\mathrm{RCH}_{4}$ seja expressa na unidade de $\mathrm{g} / \mathrm{d}$.

O potencial de emissão de metano foi expresso em diferentes unidades, como: gramas por dia ( $\mathrm{g} / \mathrm{dia})$, quilos de metano por quilos de consumo de matéria seca ( $\mathrm{kg} / \mathrm{kg} \mathrm{CMS}$ ), quilos por quilos de ganho médio diário ( $\mathrm{kg} / \mathrm{kg}$ GMD), gramas por quilos de peso vivo ( $\mathrm{g} / \mathrm{kg} \mathrm{PV}$ ), e a porcentagem de energia bruta perdida na forma de $\mathrm{CH}_{4}(\mathrm{YM} \%)=$ relação percentual entre a energia perdida na forma de metano e a energia bruta ingerida.

\subsection{Terminação em confinamento}

A terminação em confinamento teve duração de 105 dias e aconteceu entre junho e setembro de 2015, quando os 46 animais atingiram $354 \pm 41 \mathrm{~kg}$ de peso médio. O confinamento era provido de 4 baias coletivas de $396 \mathrm{~m}^{2}$, equipadas com bebedouro, amostrador de metano $\left(\right.$ Greenfeed $^{\circledR}$ ) e 2 cochos automatizados (GrowSafe ${ }^{\circledR}$ Systems Ltd., Airdrie, Alberta, Canadá) (Figura 4) cada, onde eram ofertados água e alimento ad libitum. 
Figura 5 - Animais visitando os cochos automatizados no período de terminação em confinamento

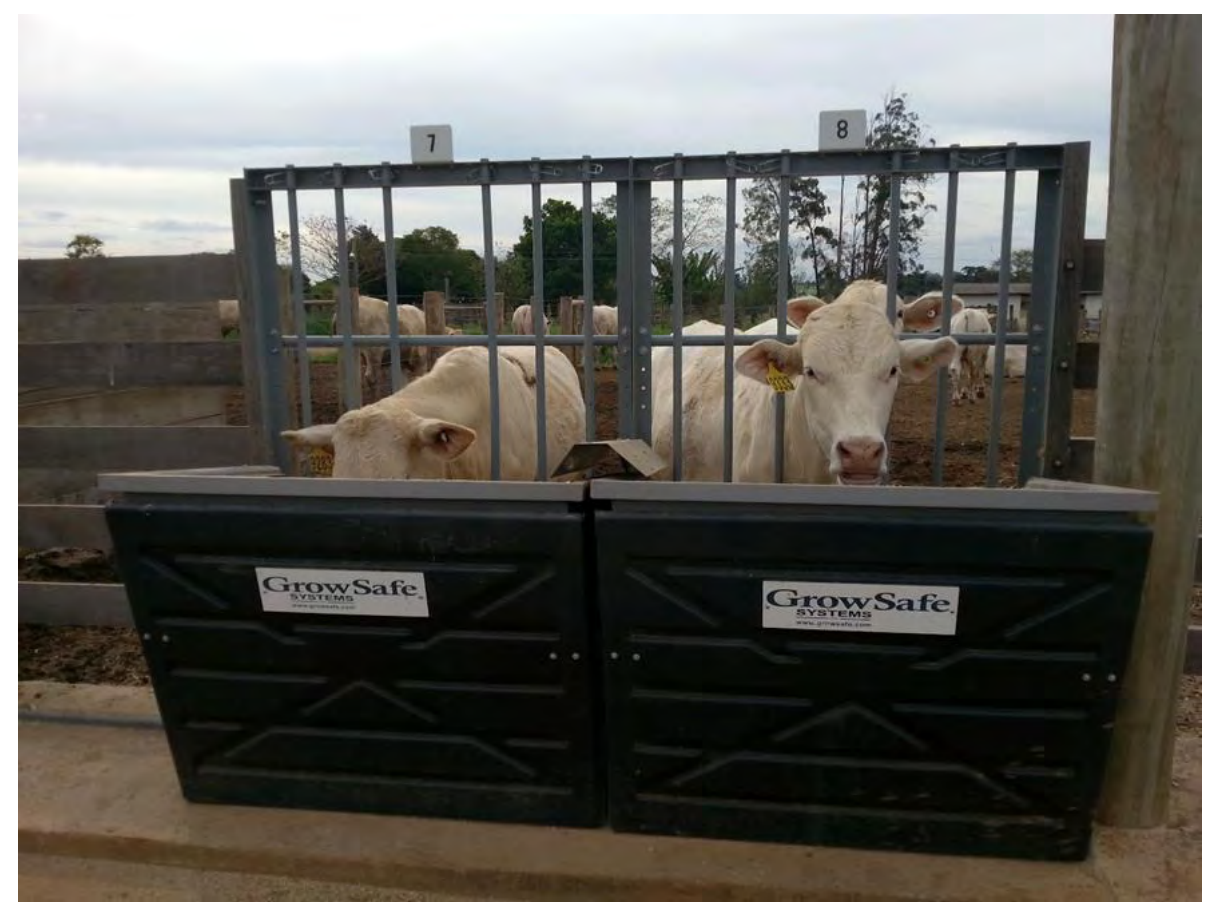

Fonte: Própria autoria.

A duração do período de adaptação foi de 20 dias, sendo que nos primeiros 10 dias os animais receberam apenas silagem de milho, nos 10 posteriores $50 \%$ do concentrado junto a silagem de milho, passando a $100 \%$ do concentrado ao término desse período, a composição da dieta está descrita na Tabela 1. Semanalmente foram coletadas amostras da dieta completa e silagem para determinação da MS realizada em estufa a $65^{\circ} \mathrm{C}$ pelo período de $72 \mathrm{~h}$. O trato foi realizado diariamente em dois períodos, às 8:00 e às 14:00 horas. Foram realizadas pesagens em jejum ao início e término do período em confinamento e neste intervalo sem jejum a cada 28 dias para acompanhamento do ganho de peso. O grau de acabamento dos animais foi acompanhado pela técnica de ultrassom in vivo e para a obtenção das imagens foi utilizado o aparelho da marca Pie Medical, modelo Áquila equipado com transdutor linear de 3,5 MHz e $18 \mathrm{~cm}$, e óleo vegetal como acoplante. Todas medidas foram efetuadas entre a $12^{\underline{a}}$ e $13^{\underline{a}}$ costelas sobre o músculo Longissimus thoracis segundo a metodologia de Herring et al. (1994). Através das medidas de ganho de peso em confinamento, e consumo de matéria seca, foram determinados o GMD, CA e EA. 
Tabela 1 - Composição da dieta experimental

\begin{tabular}{lc}
\hline \multicolumn{1}{c}{ Ingredientes } & Proporção na Dieta (\%) \\
\hline Silagem de Milho & 37,7 \\
Milho Grão Moído & 35,5 \\
Farelo de Soja & 12,5 \\
Farelo de Trigo & 10,9 \\
Calcário Calcítico & 1,1 \\
Mistura Mineral* & 1,6 \\
Ureia & 0,8 \\
Monensina Sódica & 0,03 \\
\hline & Composição Bromatológica** (\%) \\
\hline MS & 36,6 \\
PB & 15,2 \\
NDT & 72,1 \\
FDN & 32,2 \\
FDA & 17,7 \\
EE & 4,4 \\
\hline
\end{tabular}

* Níveis de garantia por kg de produto: Cálcio: 180g; lodo: 90mg; Fósforo: 130g; Manganês: 2g; Zinco: 5,27g; Cobalto: 100mg; Flúor (máx.): 1,3g; Cobre: 1,25g; Ferro: 2,2g; Selênio: 15g

** $M S=$ matéria seca; $P B=$ proteína bruta; NDT = nutrientes digestíveis totais; FDN = fibra em detergente neutro; FDA = fibra em detergente ácido; $E E$ = extrato etéreo

\subsubsection{Avaliação da produção de metano entérico durante o período de terminação em confinamento}

Para determinar a emissão de metano entérico no período de terminação foi utilizado o sistema automatizado GreenFeed $^{\circledR}$ (GF), disponível no confinamento experimental, onde os equipamentos foram instalados nas laterais das baias ocupadas por animais das linhagens antiga e nova (Figura 5). Durante os primeiros 7 dias o acesso ao aparelho permaneceu livre de forma a incentivar a visitação ao mesmo, após identificada no sistema a visita de todos os animais componentes de cada lote, o acesso ao aparelho foi fechado de forma a restringir o acesso a um animal de cada vez. Os equipamentos foram programados através do software disponibilizado pela empresa C-Lock Inc. para fornecer um máximo de 6 rotações do copo dosador de alimento, fornecendo aproximadamente $55 \mathrm{~g}$ por rotação, com intervalos de $45 \mathrm{~s}$ entre cada rotação, de modo que no máximo $330 \mathrm{~g}$ de pellet poderiam ser fornecidos a cada visita. Foi permitido um máximo de 5 visitas por dia, com um intervalo mínimo de 4:45 h exigido entre visitas. Dessa forma, se um animal 
retornasse ao aparelho em um período inferior a este intervalo os pellets não eram liberados.

Figura 6 - Animal durante visita ao equipamento GreenFeed ${ }^{\circledR}$

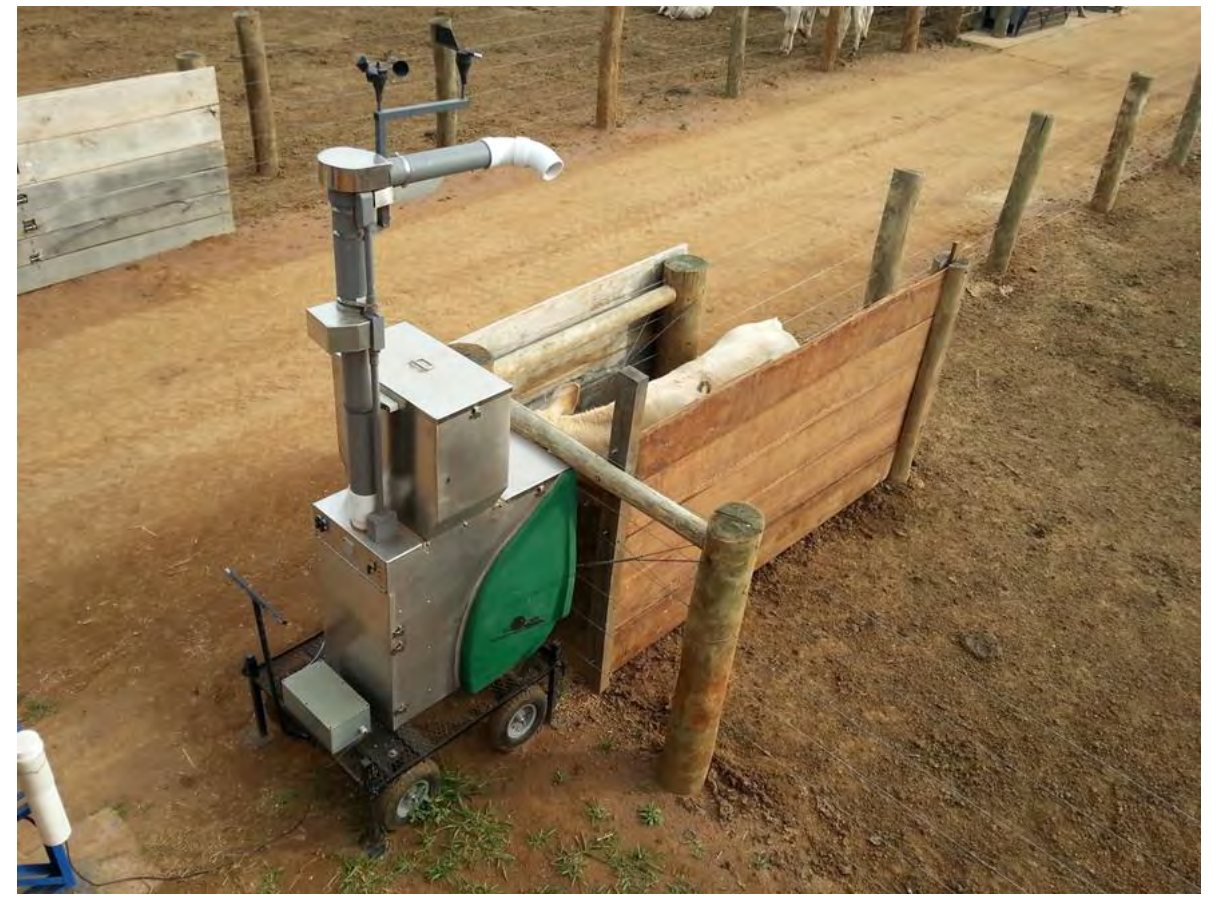

Fonte: Própria autoria.

Foram utilizados pellets comerciais destinados a alimentação de coelhos (Presence do Campo - Coelhos, In Vivo Nutrição e Saúde Animal, Paulínia, São Paulo, Brasil), por apresentarem maior teor de fibra e com níveis de garantia de $13 \%$ de umidade, $14 \%$ de proteína bruta, $3 \%$ de extrato etéreo, $14 \%$ de matéria mineral, $20 \%$ de fibra bruta, $1,2 \%$ de cálcio e $0,6 \%$ de fósforo. A operação do aparelho tinha início no momento que os animais inseriam a cabeça no interior do cocho e um sensor de identificação por rádio frequência (RFID) identificava o chip fixo a orelha do animal. A amostragem de gases só era iniciada quando a cabeça do animal estava na posição correta identificada por um sensor infravermelho, o que resultava na distribuição de pellets atraindo e encorajando o animal a manter a cabeça na posição correta. Este fator além da velocidade e direção do vento determinavam o sucesso da leitura, uma vez que a posição da cabeça do animal além do vento podia variar, mas somente os 
dados com medições ininterruptas foram considerados válidos para a análise estatística.

Os equipamentos GF foram zerados e calibrados semanalmente com o uso "gás padrão zero" (nitrogênio livre de oxigênio) e uma mistura de gases para calibração contendo $0,5 \mathrm{cmol} / \mathrm{mol}$ de dióxido de carbono e $\mu \mathrm{mol} / \mathrm{mol}$ de metano (Indústria Brasileira de Gases, Jundiaí, São Paulo, Brasil). O tubo de exaustão era equipado com filtro de ar, que filtrava e removia qualquer material particulado fino do ar que era subamostrado de forma a evitar danos aos sensores. O filtro foi substituído e lavado periodicamente, sempre que o programa apontava fluxo de ar abaixo de 25 $\mathrm{L} / \mathrm{s}$. A concentração de $\mathrm{CH}_{4}$ foi determinada por um sensor infravermelho nãodispersivos (NDIR) e o volume de ar deslocado no tubo de exaustão foi determinado por anemômetro ultrassônico. O fluxo de metano entérico emitido pelo animal foi calculado considerando a concentração de metano da amostra e o volume de ar deslocado pela exaustão. A comunicação em tempo real entre as unidades GF e o software disponibilizado pela C-Lock inc. na web foi possível via rede Wi-Fi. De maneira similar a mensuração da emissão de $\mathrm{CH}_{4}$ durante o período de recria a pasto, os resultados do período de terminação em confinamento foram expressos em: g/dia; (kg/kg CMS); (kg/kg GMD); (g/kg PV) e YM (\%).

\subsection{Abate}

Os animais foram destinados ao abate quando atingiram em média $488 \pm 48$

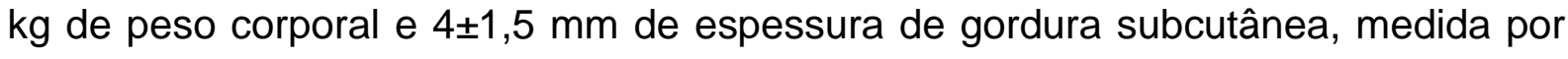
ultrassonografia. $\mathrm{O}$ abate foi realizado em frigorífico comercial, registrado no Sistema de Inspeção Estadual, de acordo com a rotina do mesmo. Após a insensibilização, sangria, evisceração e toalete, foram coletadas informações sobre o peso de carcaça quente, e após 24 horas de resfriamento em câmara fria, foram coletadas informações do peso da carcaça fria (Figura 6). Com estas duas medidas, foram calculados os rendimentos de carcaça quente e fria, baseado no peso ao abate, e a quebra no processo de resfriamento por diferença (\%) no peso da carcaça quente e fria. $O$ rendimento de carcaça fria $(\mathrm{RCF})$ foi calculado através da relação percentual entre o peso vivo final (PVF) e o peso de carcaça fria (PCF), obtido através da equação: 


$$
R C F(\%)=\frac{P C F \times 100}{P V F}
$$

Figura 7 - Carcaças após período de resfriamento de 24 h

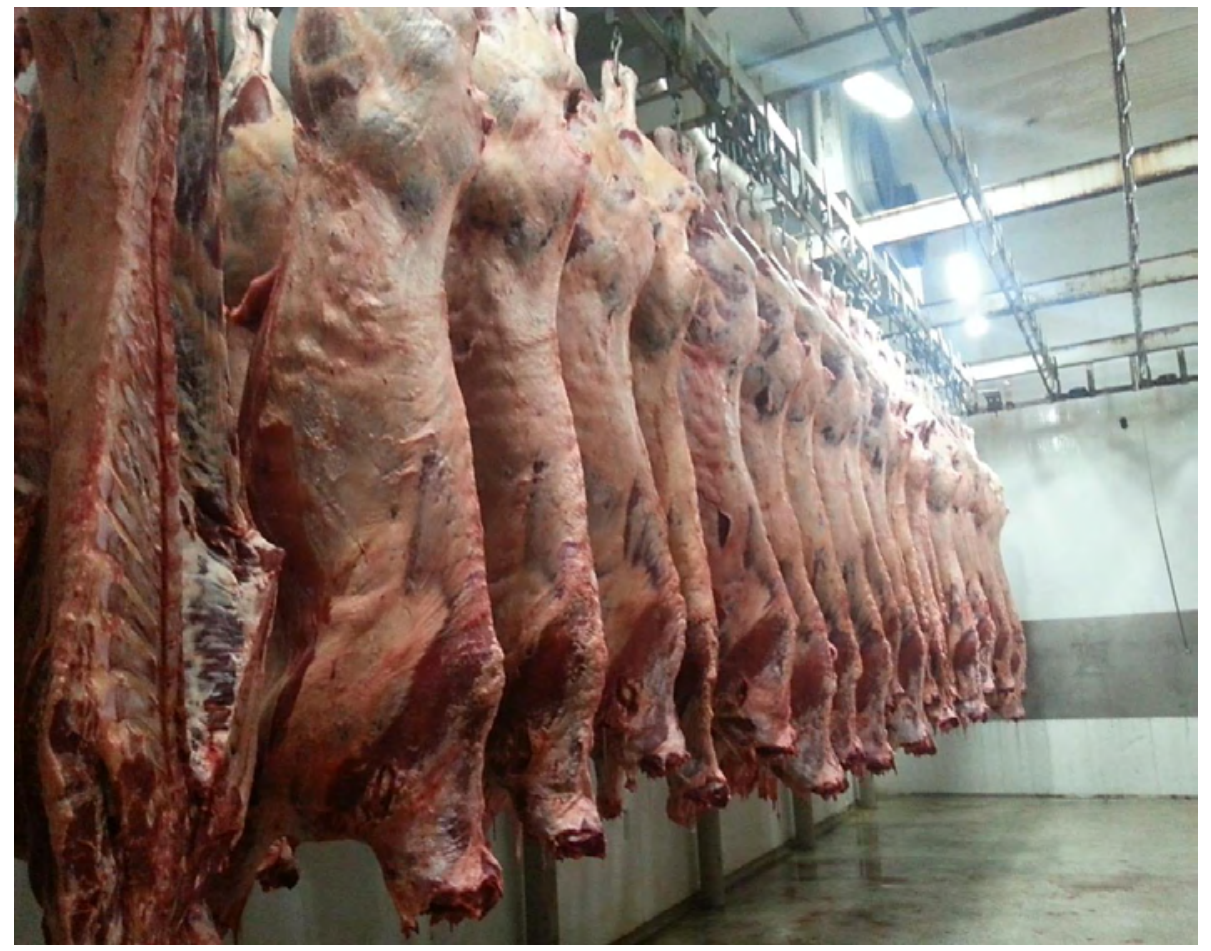

Fonte: Própria autoria.

Após o resfriamento e separação das carcaças em dianteiro e traseiro, foram coletados os pesos dos cortes principais (traseiro especial, ponta de agulha e dianteiro). Uma amostra do músculo Longissimus thoracis da carcaça esquerda foi retirada entre a $12^{\mathrm{a}}$ e a $13^{\mathrm{a}}$ costela para mensuração real da $A O L$ e $E G$, utilizando-se papel vegetal + grade reticulada $\left(\mathrm{cm}^{2}\right)$ e régua milimetrada, respectivamente. Posteriormente, foi realizada a desossa da carcaça direita, na qual houve a separação em cortes comerciais e retalhos (retalhos de carne, gordura/aparas e ossos), realizada no traseiro e no dianteiro. A ponta de agulha não foi desossada. Foram considerados como cortes comerciais do dianteiro: paleta + músculo dianteiro, acém + pescoço e peito. Os cortes comerciais do traseiro foram: contra-filé, filé mignon, cordão do filé, alcatra, maminha, picanha, picanha grill, coxão mole, coxão duro, lagarto, patinho e fraldão. Os cortes secundários do traseiro foram: bananinha, capa do filé, músculo e aranha. 


\subsection{Análise estatística dos dados}

A análise dos dados foi realizada através do pacote STATICAL ANALYSIS SYSTEM 9.3 (SAS Inst. Inc., Cary, NC). A presença de informações discrepantes (outliers) e a normalidade dos resíduos (Shapiro-Wilk) foram testadas através do procedimento PROC GLM. Os dados de desempenho e relacionados as emissões de $\mathrm{CH}_{4}$ foram analisados por meio do procedimento Proc Mixed para modelos mistos. Foram testadas 15 diferentes estruturas de covariância, e com base no critério de informação Akaike corrigido (AICC), selecionada a que melhor se ajustou ao modelo estatístico (WANG; GOONEWARDENE, 2004). No modelo foi incluído efeito fixo de tratamento (linhagem). Efeito de bloco, foi incluído no modelo como efeito aleatório.

Os dados de abate como os de desempenho, foram analisados por meio do Proc Mixed para modelos mistos. Quando a normalidade dos resíduos não foi atendida, testou-se também a distribuição de Poisson, método disponível no Proc Glimmix, componente do SAS. Em relação a todas as variáveis, foi utilizado para comparação entre os tratamentos o teste de Tukey ajustado, sendo considerado o nível de significância de $5 \%$.

Abaixo é aprestando o modelo estatístico para os dados sem medidas repetidas no tempo.

$$
Y_{i j k}=\mu+T_{i}+P_{j}+B_{k}+e_{i j k}
$$

Onde:

$$
\begin{aligned}
& Y_{i j k}=\text { Variável resposta; } \\
& \mu=\text { Média geral; } \\
& \mathrm{T}_{\mathrm{i}}=\text { Efeito fixo de tratamento; } \\
& \mathrm{Pl}_{\mathrm{j}}=\text { Efeito fixo de peso inicial (covariável); } \\
& \mathrm{B}_{\mathrm{k}}=\text { Efeito aleatório de bloco; } \\
& \mathrm{e}_{\mathrm{ijk}}=\text { Erro experimental aleatório. }
\end{aligned}
$$




\section{RESULTADOS}

\subsection{Recria a pasto}

Os resultados obtidos das variáveis de desempenho relacionadas ao período de recria a pasto, estão descritos na Tabela 2. Pode-se observar que a linhagem dos animais teve efeito significativo sobre as variáveis de ganho médio diário $(p<0,01)$, conversão alimentar $(p<0,01)$ e eficiência alimentar $(p<0,05)$. Os animais provenientes da linhagem Nova apresentaram médias superiores aos da linhagem Antiga em relação ao ganho médio diário, e eficiência alimentar, enquanto os animais pertencentes a linhagem Cruzada, não se diferenciaram dos animais da linhagem Nova tratando-se destas mesmas variáveis. Os animais pertencentes à linhagem Antiga foram menos eficientes $(p<0,01)$ em converter o alimento ingerido em quilos de peso vivo, apresentando a maior média de conversão alimentar quando comparados aos animais da linhagem Nova. Já os novilhos pertencentes a linhagem Cruzada, por sua vez não se diferenciaram aos da linhagem Nova para esta mesma variável.

Tabela 2 - Peso inicial (PI), peso final (PF), ganho médio diário (GMD), consumo de matéria seca diário (CMSD), conversão alimentar (CA), eficiência alimentar (EA) de linhagens da raça Canchim recriadas a pasto

\begin{tabular}{lccccc}
\hline \multirow{2}{*}{ Variáveis } & \multicolumn{3}{c}{ Linhagens } & \multirow{2}{*}{ EPM* $^{*}$ Valor de P } \\
\cline { 2 - 4 } & Nova & Cruzada & Antiga & & \\
\hline PI (kg) & 274,6 & 286,8 & 281,7 & 5,75 & 0,7357 \\
PF (kg) & 378,8 & 383,4 & 362,4 & 6,65 & 0,6433 \\
GMD (kg/d) & $0,692^{\mathrm{a}}$ & $0,620^{\mathrm{ab}}$ & $0,547^{\mathrm{b}}$ & 0,04 & 0,0002 \\
CMSD (kg /d) & 6,49 & 6,38 & 6,06 & 0,15 & 0,2717 \\
CA (kg MS/kg GMD) & $10,67^{\mathrm{b}}$ & $12,95^{\mathrm{ab}}$ & $13,97^{\mathrm{a}}$ & 0,89 & 0,0098 \\
EA (\%) & $9,9^{\mathrm{a}}$ & $9,3^{\mathrm{ab}}$ & $8,5^{\mathrm{b}}$ & 0,48 & 0,0150 \\
\hline
\end{tabular}

a,b médias seguidas de letras minúsculas diferentes nas linhas, diferem entre si a $(p<0,05)$, pelo teste de Tukey

${ }^{\star} \mathrm{EPM}=$ erro padrão das médias

Na Tabela 3, são descritos os resultados das variáveis de emissão de metano entérico, relativos ao período de recria a pasto. Não houve efeito da linhagem dos animais sobre a emissão de metano, mesmo expresso em diferentes unidades. 
Tabela 3 - Fatores de emissão de metano de linhagens de bovinos Canchim recriados a pasto

\begin{tabular}{lcccc}
\hline \multirow{2}{*}{ Emissão de $\mathrm{CH}_{4}$} & \multicolumn{2}{c}{ Linhagens } & \multirow{2}{*}{ EPM** } & \multirow{2}{*}{ Valor de P } \\
\cline { 2 - 3 } & Nova & Antiga & & \\
\hline g/dia & 212,89 & 193,98 & 10,63 & 0,3835 \\
kg/kg CMS* & 0,031 & 0,031 & 0,0011 & 0,9860 \\
kg/kg GMD* & 0,324 & 0,337 & 0,0194 & 0,7483 \\
g/kg PV* & 0,562 & 0,557 & 0,0260 & 0,9304 \\
YM* (\%) & 9,41 & 9,42 & 0,72 & 0,9882 \\
\hline
\end{tabular}

a,b médias seguidas de letras minúsculas diferentes nas linhas, diferem entre si a $(p<0,05)$, pelo teste de Tukey.

* $\mathrm{CMS}=$ Consumo de matéria seca, $\mathrm{GMD}=$ Ganho médio diário, $\mathrm{PV}=$ Peso vivo, $\mathrm{YM}(\%)=$ relação percentual entre a energia perdida na forma de metano e a energia bruta ingerida

**EPM = erro padrão das médias

\subsection{Terminação em confinamento}

No período de terminação em confinamento de 105 dias houve efeito de linhagem para as variáveis ganho médio diário $(p<0,05)$, consumo de matéria seca diário $(p<0,05)$ e conversão alimentar $(p<0,01)$ (Tabela 4). A linhagem nova foi superior $(p<0,05)$ no ganho médio diário em relação à linhagem antiga, enquanto a linhagem cruzada não se diferenciou da nova nestas variáveis. Os maiores consumos diários de matéria seca foram observados nos animais pertencentes as linhagens nova e cruzada em relação a linhagem antiga. Os animais cruzados apresentaram maior média $(p<0,05)$ de conversão alimentar comparados aos animais LN e LA.

As emissões relativas ao período de terminação em confinamento são descritas na Tabela 5. A linhagem dos animais teve efeito $(p<0,05)$ sobre a emissão de $\mathrm{CH}_{4}$ expressa em em gramas por dia (g/dia). Animais pertencentes à linhagem nova emitiram mais metano $(p<0,05)$ em relação a linhagem antiga quando essa variável foi expressa em gramas por dia. 
Tabela 4 - Peso Inicial (PI), peso final (PF), ganho médio diário (GMD), ganho por período (GPP), consumo de matéria seca diário (CMSD), conversão alimentar (CA), eficiência alimentar (EA), de linhagens da raça Canchim terminados em confinamento

\begin{tabular}{lccccc}
\hline \multirow{2}{*}{ Variáveis } & \multicolumn{3}{c}{ Linhagens } & \multirow{2}{*}{ EPM* $^{*}$ Valor de P } \\
\cline { 2 - 4 } & Nova & Cruzada & Antiga & & \\
\hline PI (kg) & 378,8 & 383,4 & 362,4 & 7,43 & 0,2607 \\
PF (kg) & 523,8 & 517,1 & 484,6 & 7,86 & 0,2008 \\
GMD (kg/d) & $1,44^{\mathrm{a}}$ & $1,32^{\mathrm{ab}}$ & $1,23^{\mathrm{b}}$ & 0,06 & 0,0144 \\
CMSD (kg/d) & $10,25^{\mathrm{a}}$ & $10,42^{\mathrm{a}}$ & $9,11^{\mathrm{b}}$ & 0,20 & 0,0289 \\
CA (kg MS/kg GMD) & $6,92^{\mathrm{b}}$ & $9,10^{\mathrm{a}}$ & $7,46^{\mathrm{b}}$ & 0,29 & $<0,0001$ \\
EA (\%) & 14,5 & 13,1 & 14,0 & 0,57 & 0,1544 \\
\hline
\end{tabular}

a,b médias seguidas de letras minúsculas diferentes nas linhas, diferem entre si a $(p<0,05)$, pelo teste de Tukey

${ }^{\star} E P M=$ erro padrão das médias

Tabela 5 - Fatores de emissão de $\mathrm{CH}_{4}$ e $\mathrm{CO}_{2}$ de linhagens de bovinos Canchim terminados em confinamento

\begin{tabular}{lcccc}
\hline \multirow{2}{*}{ Emissões de $\mathrm{CH}_{\mathbf{4}}$} & \multicolumn{2}{c}{ Linhagens } & \multirow{2}{*}{ EPM** } & \multirow{2}{*}{ Valor de P } \\
\cline { 2 - 3 } & Nova & Antiga & & \\
\hline g/dia & $178,18^{\mathrm{a}}$ & $156,31^{\mathrm{b}}$ & 7,39 & 0,0155 \\
kg/kg CMS* & 0,0172 & 0,0163 & 0,0007 & 0,2592 \\
kg/kg GMD* & 0,149 & 0,124 & 0,011 & 0,0578 \\
g/kg P* & 0,379 & 0,371 & 0,0179 & 0,7235 \\
YM (\%) & 5,19 & 5,07 & 0,25 & 0,6901 \\
\hline
\end{tabular}

$a, b$ médias seguidas de letras minúsculas diferentes nas linhas, diferem entre si a $(p<0,05)$, pelo teste de Tukey.

* $\quad \mathrm{CMS}=$ Consumo de matéria seca, $\mathrm{GMD}=$ Ganho médio diário, $\mathrm{PV}=$ Peso vivo, $\mathrm{YM}(\%)=$ relação percentual entre a energia perdida na forma de metano e a energia bruta ingerida

${ }^{*} E P M=$ erro padrão das médias

\subsection{Abate}

Os pesos e rendimentos de carcaça quente e fria, dos cortes principais e a perda por resfriamento são descritos na Tabela 6 , pode-se observar que não houve efeito significativo $(p>0,05)$ da linhagem dos animais para nenhuma das variáveis de carcaça estudadas. 
Tabela 6 - Peso de carcaça quente (PCQ), peso de carcaça fria (PCF), Rendimento de carcaça quente (RCQ), rendimento de carcaça fria (RCF), perda por resfriamento (PPR), peso de traseiro (PT), peso de dianteiro (PD), peso da ponta de agulha (PPA), de linhagens de bovinos Canchim

\begin{tabular}{lcccccc}
\hline \multirow{2}{*}{ Variáveis } & \multicolumn{3}{c}{ Linhagens } & Média & EPM* & Valor de P \\
\cline { 2 - 4 } & Nova & Cruzada & Antiga & & & \\
\hline PCQ (kg) & 267,5 & 266,3 & 248,3 & 261,7 & 7,00 & 0,1160 \\
PCF (kg) & 263,7 & 262,0 & 244,0 & 257,6 & 6,94 & 0,1055 \\
RCQ (\%) & 53,9 & 54,3 & 54,2 & 54,1 & 0,32 & 0,5420 \\
RCF (\%) & 53,1 & 53,4 & 53,2 & 53,2 & 0,31 & 0,6902 \\
PPR (\%) & 1,47 & 1,64 & 1,76 & 1,59 & 0,09 & 0,1170 \\
PT (kg) & 130,0 & 129,4 & 120,9 & 127,3 & 3,40 & 0,1268 \\
PD (kg) & 98,9 & 98,7 & 92,4 & 97,0 & 2,57 & 0,1565 \\
PPA (kg) & 34,8 & 33,9 & 30,7 & 33,4 & 1,22 & 0,0581 \\
\hline
\end{tabular}

$a, b$ médias seguidas de letras minúsculas diferentes nas linhas, diferem entre si a $(p<0,05)$, pelo teste de Tukey

*EPM = erro padrão das médias

$\mathrm{Na}$ Tabela 7, são apresentadas as médias de espessura de gordura subcutânea (EG), e área de olho de lombo (AOL). A linhagem teve efeito significativo $(p<0,05)$ sobre o acabamento dos animais, sendo que a $E G$ foi maior nas carcaças provenientes dos animais da linhagem nova em relação as da $L A$, enquanto a $E G$ medida nas carcaças dos animais cruzados foi estatisticamente igual $(p>0,05)$ a das carcaças da linhagem nova.

Os pesos dos cortes cárneos comercias são descritos na Tabela 8, onde, a linhagem influenciou significativamente $(p<0,05)$ apenas os cortes capa de filé e fraldão, sendo que a linhagem nova e os novilhos cruzados apresentaram maior peso de capa de filé comparadas a LA. Tratando-se do corte fraldão foram obtidas peças mais pesada das carcaças pertencentes a LN quando comparadas a linhagem antiga, já os cruzados não se diferenciaram da linhagem nova. 
Tabela 7 - Espessura de gordura subcutânea (EG) e área de olho de lombo (AOL) de linhagens de bovinos da raça Canchim

\begin{tabular}{lcccccc}
\hline \multirow{2}{*}{ Variáveis } & \multicolumn{3}{c}{ Linhagens } & \multirow{2}{*}{ Média } & EPM* & Valor de P \\
\cline { 2 - 4 } & Nova & Cruzada & Antiga & & & \\
\hline EG $(\mathbf{m m})$ & $4,36^{\mathrm{a}}$ & $3,80^{\mathrm{ab}}$ & $3,17^{\mathrm{b}}$ & 3,81 & 0,40 & 0,0131 \\
AOL $\left(\mathrm{cm}^{2}\right)$ & 75,79 & 71,34 & 73,14 & 73,78 & 2,07 & 0,2857 \\
\hline
\end{tabular}

a,b médias seguidas de letras minúsculas diferentes nas linhas, diferem entre si a $(p<0,05)$, pelo teste de Tukey

${ }^{*} E P M=$ erro padrão das médias

Tabela 8 - Peso dos cortes cárneos comercias de linhagens de bovinos da raça Canchim recriados a pasto e terminados em confinamento

\begin{tabular}{lcccccc}
\hline \multirow{2}{*}{ Variáveis } & \multicolumn{3}{c}{ Linhagens } & Média & EPM* & $\begin{array}{c}\text { Valor de } \\
\text { P }\end{array}$ \\
\cline { 2 - 4 } & Nova & Cruzada & Antiga & & & 0,1863 \\
\hline Paleta + M. Dianteiro (kg) & 14,90 & 14,71 & 13,89 & 14,56 & 0,40 & 0,15 \\
Acém + Pescoço (kg) & 15,50 & 15,85 & 15,15 & 15,50 & 0,46 & 0,6055 \\
Peito (kg) & 5,51 & 5,44 & 5,16 & 5,38 & 0,13 & 0,1604 \\
Bananinha (kg) & 0,52 & 0,49 & 0,48 & 0,50 & 0,02 & 0,3768 \\
Contra-Filé (kg) & 7,67 & 7,90 & 7,05 & 7,56 & 0,23 & 0,0568 \\
Filé-Mignon (kg) & 1,86 & 1,89 & 1,89 & 1,88 & 0,06 & 0,8961 \\
Capa de Filé (kg) & $1,27^{\text {a }}$ & $1,30^{\mathrm{a}}$ & $1,06^{\mathrm{b}}$ & 1,22 & 0,06 & 0,0151 \\
Cordão do F. Mignon (kg) & 0,25 & 0,27 & 0,26 & 0,26 & 0,01 & 0,6028 \\
M. Alcatra + Maminha (kg) & 5,14 & 5,39 & 5,04 & 5,18 & 0,15 & 0,2830 \\
Picanha Grill (kg) & 0,91 & 0,73 & 0,75 & 0,81 & 0,08 & 0,1559 \\
Coxão Mole (kg) & 9,31 & 9,62 & 9,03 & 9,32 & 0,24 & 0,2927 \\
Coxão Duro (kg) & 4,65 & 4,61 & 4,39 & 4,57 & 0,13 & 0,3345 \\
Lagarto (kg) & 2,51 & 2,38 & 2,35 & 2,43 & 0,08 & 0,3031 \\
Patinho (kg) & 5,46 & 5,52 & 5,33 & 5,44 & 0,15 & 0,7304 \\
Músculo (kg) & 4,48 & 4,50 & 4,24 & 4,42 & 0,12 & 0,3165 \\
Aranha (kg) & 0,25 & 0,25 & 0,23 & 0,24 & 0,01 & 0,5561 \\
Fraldão (kg) & $2,20^{\mathrm{a}}$ & $2,09^{\mathrm{ab}}$ & $1,93^{\mathrm{b}}$ & 2,09 & 0,07 & 0,0436 \\
\hline
\end{tabular}

a,b médias seguidas de letras minúsculas diferentes nas linhas, diferem entre si a $(p<0,05)$, pelo teste de Tukey

${ }^{\star}$ EPM = erro padrão das médias 


\section{DISCUSSÃO}

O maior ganho médio diário desempenhado pela linhagem nova no período de recria a pasto foi decorrente da melhor eficiência alimentar apresentada pelos animais desta linhagem, uma vez que o consumo de alimento entre os animais das duas linhagens (Nova e Cruzada), não diferiu. Consequentemente a linhagem nova apresentou melhor conversão alimentar, já que para cada $\mathrm{kg}$ de peso vivo depositado foram necessários $3,3 \mathrm{~kg}$ a menos de matéria seca ingerida em relação à linhagem antiga. De acordo com Alencar (1997), as características de desempenho na raça Canchim, apresentam, em geral, valores médios a altos de herdabilidade, sinalizando que a seleção resulta em bom progresso genético, evidenciado neste trabalho na linhagem nova. Além disso, diversas pesquisas avaliaram cruzamentos e constataram que quando a raça Charolesa é incluída, há um maior efeito genético aditivo nas características relacionadas ao desempenho, taxa de crescimento, peso adulto e desenvolvimento muscular (PEACOCK et al., 1979; MENEZES et al., 2005). Esta constatação é relevante para o presente trabalho, pois a raça Canchim é composta por $5 / 8$ de raça charolesa. $O$ desempenho animal é um princípio importante quando o objetivo da exploração dos bovinos é a produção de carne. Usualmente, a evolução dos animais é avaliada com base no ganho de peso, que pode ser medido em diferentes fases da vida do animal (cria, recria, engorda).

Barbero et al. (2014) trabalharam com novilhos Nelore em pastagens de capim Tanzânia com diferentes alturas de desfolha (20; 40; 60 e $80 \mathrm{~cm})$, durante as quatro estações do ano, observando no verão e outono, estações equivalentes ao período avaliado no presente trabalho, ganhos médios diários mais elevados, independente da altura avaliada. Os mesmos autores atestam que o pastejo entre 40 e $60 \mathrm{~cm}$ promove boa associação entre o ganho médio diário e a produção de forragem por hectare. Cano et al. (2004) afirmam que o capim Tanzânia sob pastejo entre $40 \mathrm{e}$ $60 \mathrm{~cm}$ apresenta composição química e digestibilidade compatíveis com forragens de bom valor nutritivo e que o aumento da altura do dossel forrageiro promove a redução do valor nutritivo em termos da digestibilidade, proteína bruta, concentração de minerais e incremento nos teores de fibra (FDN e FDA). Como pode ser observado na figura 3 , durante todo o período de recria a pasto a altura de pastejo foi superior a $60 \mathrm{~cm}$, demonstrando que as técnicas de manejo empregadas não foram efetivas em 
adequar a altura do pasto ao ponto ideal destacado pela literatura. Esse fato, pode explicar o ganho médio diário abaixo e emissão de metano acima do atestado na literatura, para pastagens de capim Tanzânia manejadas de forma intensiva.

Estudando animais Canchim em regime exclusivo de pastejo, Vieira (1975), obteve um ganho médio de $0,375 \mathrm{~kg} / \mathrm{dia}$, valor inferior aos observados neste trabalho para as linhagens nova $(0,692 \mathrm{~kg} / \mathrm{dia})$, antiga $(0,620 \mathrm{~kg} / \mathrm{dia})$, bem como sua cruza $(0,547 \mathrm{~kg} / \mathrm{dia})$, submetidas à pastagem de elevado valor nutricional e grande disponibilidade. O trabalho de Vieira (1975) foi um dos pioneiros relacionados ao desempenho da raça Canchim, onde o progresso genético na raça era com base apenas em observações do comportamento das diferentes combinações de raças e não como resultado de um processo seletivo já estabelecido, ainda não havendo horizonte para formação de uma nova linhagem. Alencar et al. (1989), ao comparar animais das raças Canchim e Nelore de ambos os sexos em regime de pastejo, encontraram diferença no ganho de peso diário e identificaram maiores ganhos para os machos Canchim em relação às outras categorias. Goulart et al. (2006) também encontraram diferentes ganhos médios diários em pesquisa com animais Nelore e cruzados Canchim X Nelore, Angus $X$ Nelore e Simental $X$ Nelore recriados em pastagem, onde os animais provenientes do grupo genético Angus $X$ Nelore apresentaram maior ganho, porém não identificaram diferenças significativas em relação a eficiência e conversão alimentar.

No período de terminação em confinamento, o maior ganho médio diário apresentado pela linhagem nova $(1,44 \mathrm{~kg} / \mathrm{dia})$, pode ser explicado pela maior ingestão de alimento e menor valor para conversão alimentar desempenhados pela mesma; a linhagem antiga, apesar de conversão alimentar equivalente à da nova, não obteve ganho similar por ter apresentado consumo de matéria seca mais baixo. Os animais da linhagem cruzada apesar de apresentarem consumo maior que a linhagem antiga, não ganharam mais peso porque a conversão alimentar foi pior do que a linhagem antiga. Hegarty et al. (2014) trabalharam em confinamento com linhagens da raça Angus, selecionadas para baixo ou alto consumo alimentar residual, e obtiveram diferenças significativas em relação à ingestão de matéria seca e a produção de metano diária, sendo que os animais que apresentaram maior consumo emitiram maior quantidade de metano entérico, por outro lado não observaram diferenças no ganho médio diário e na produção de metano expressa em relação ao ganho diário e 
o consumo de matéria seca, como também observado no presente trabalho. Fernandes et al. (2007) trabalharam em confinamento com animais Canchim de diferentes condições sexuais (machos inteiros/castrados e fêmeas) e observaram ganho de peso, consumo de matéria seca e conversão alimentar significativamente diferentes, sendo que os animais Canchim não castrados apresentaram as melhores médias em relação a estas três variáveis. Diferenças estatísticas nestas mesmas características também foram observadas por Rubiano et al. (2009) que estudaram em confinamento animais Nelore, Canchim e o cruzamento entre estas raças, identificando superioridade da raça Canchim. O maior ganho de peso é esperado quando há uma maior ingestão de matéria seca, já que estas características são positivamente correlacionadas (HERD, et al., 2014).

O maior GMD e melhor CA encontrados neste trabalho são coerentes com os resultados de Trematore et al. (1998) que afirmaram que quanto maior a porcentagem de genes da raça Charolesa na prole, maior pode ser o seu desempenho a pasto ou em confinamento. O efeito da raça charolesa sobre o desempenho também foi confirmada por Crews et al. (2004) que estudaram parâmetros genéticos entre características de crescimento e carcaça de animais Charolês e afirmaram que a herdabilidade para as mesmas é de moderada a alta nesta raça, indicando que a seleção pode ser utilizada para melhorar tanto os padrões de crescimento quanto a conformação de carcaça. A raça Canchim apresenta variação genética aditiva em relação ao ganho de peso e há melhora nessa característica com o passar do tempo, como descrito por Chaves et al. (2005), e confirmadas com os resultados apresentados dos animais da linhagem nova. Barrichello (2007) também afirmou que a seleção genética empregada na raça Canchim vem proporcionando progresso nas características de peso e conformação frigorífica. Em trabalho clássico, Koch (1963) descreve que a seleção para o ganho de peso é eficaz e conduz a uma maior eficiência alimentar, além de um aumento no consumo de alimento, efeitos observados neste trabalho para a linhagem nova (10,25 kg de consumo diário e 14,5\% de eficiência alimentar) quando comparados à linhagem antiga (9,11 kg e 14,0\%). Ao se selecionar para eficiência alimentar ocorre ganho genético para esta característica, o que resulta em um maior ganho diário, porém não havendo aumento no consumo alimentar. 
Em relação à avaliação da emissão de metano entérico na pastagem, diferentes trabalhos de pesquisa comparam as emissões obtidas através da técnica do gás traçador $\mathrm{SF}_{6}$ com os resultados obtidos dos mesmos animais em câmaras respirométricas, e encontram em média uma variação de 7,5\% para mais ou para menos nas emissões (HAMMOND, et al., 2016), com isso a técnica apresenta resultados mais variáveis o que aumenta a demanda de animais necessários para identificar diferenças de tratamento (STORM, et al., 2012). O número de 12 animais por tratamento medidos através da técnica do SF6 neste experimento não foi um número pequeno, mas pode não ter configurado número suficiente de animais para detectar diferença na produção de metano entre a linhagem nova e antiga. Segundo Mercadante et al. (2015), não existem evidências que animais de maior eficiência produzam menos metano entérico, mesmo se apresentarem menor consumo de alimentos e desempenho equivalente ao de animais considerados ineficientes. Sakamoto et al. (2015) avaliaram as emissões de animais Canchim criados em diferentes sistemas de pastagem (intensivo, extensivo, ILP, ILPF e silvipastoril) e não identificaram diferenças significativas para a emissão de $\mathrm{CH}_{4}$ expressa em gramas por dia.

A maior emissão de metano entérico dos animais da linhagem nova no confinamento pode estar relacionada ao maior consumo de MS, visto que há uma relação diretamente proporcional entre aumento do consumo e aumento na produção de metano (KIRCHGESSNER et al., 1991; SHIBATA; TERADA, 2010). Moss, Givens e Garnsworthy (1995), confirmaram esta informação, destacando que a produção de metano está ligada à ingestão de matéria seca, mas esse parâmetro só deve ser utilizado comparativamente quando a fonte de MS ou a dieta são únicas, assim como no presente trabalho. Também é importante destacar que outros autores atestam uma alta correlação $(r>0.60)$ entre a produção de metano e o consumo de matéria seca (BLAXTER; CLAPPERTON, 1965, HERD et al., 2014). De forma geral as emissões médias de metano determinadas neste experimento (67 kg/ano) foram pouco acima, mas estão coerentes com as estimativas realizadas utilizando a metodologia do Tier 2 do IPCC (64 kg/ano) (IPCC, 2006). A seleção genética para menor produção de metano pode trazer efeitos indesejáveis para a produtividade anima I, já que a seleção por esta característica pode conduzir a produção de animais com crescimento mais 
baixo (DONOGHUE, et al., 2016), neste trabalho a linhagem antiga apesar de emitir menos metano apresentou menor ganho médio diário e maior conversão alimentar.

A maior EGS apresentada pelos novilhos da linhagem nova neste trabalho, pode estar ligada ao maior ganho médio diário apresentado pelos animais no período de recria a pasto e na terminação em confinamento. De acordo com Di Marco (2007), a raça, histórico alimentar e velocidade de ganho de peso são características que podem condicionar a quantidade de gordura subcutânea depositada. Alguns trabalhos mostram resultados relacionados à deposição de gordura. Fernandes et al. (2007) avaliando o desempenho e características de carcaça de bovinos Canchim machos inteiros e castrados, além de fêmeas, detectaram deposição de gordura subcutânea semelhantes entre as diferentes categorias avaliadas. A raça Canchim é tardia em relação à deposição de gordura, sendo que esta característica é mais expressiva próxima ao peso adulto dos animais e, de acordo com Alencar et al. (1994), o uso da raça Charolesa atribuiu além de outras características, maior velocidade de crescimento e porte mais avantajado, com consequente deposição de gordura mais tardia.

Apesar da diferença encontrada na EGS entre as linhagens nova e antiga, todas atenderam o mínimo exigido pelos frigoríficos de $3 \mathrm{~mm}$. A EGS tem papel importante no processo de transformação do músculo em carne e é determinante na qualidade da mesma, pois age como isolante térmico para que o decréscimo da temperatura ocorra de forma mais lenta, protegendo a carcaça (DOLEZAL et al., 1982; TATUM et al., 1982; YOKOO et al., 2008) e evitando o encurtamento das fibras musculares por ação do resfriamento (YOKOO et al., 2008). Esta mudança teve início dos anos 90 , onde praticamente toda a carne bovina era proveniente de animais machos magros e com 3 a 5 anos de idade (RUBIANO, 2009). A redução na idade ao abate, associada ao potencial genético dos animais vem sendo um importante caminho para produzir carne com maior eficiência e qualidade, satisfazendo 0 consumidor final. 


\section{CONCLUSÃO}

Em sistemas de produção de bovinos a pasto na fase de recria, para obter maiores ganhos de peso, melhor conversão alimentar e eficiência alimentar, deve-se utilizar animais resultantes de processos de seleção genética. A seleção genética para características de desempenho produtivo não afeta o nível de emissão de metano sob condições de pastejo.

Para animais em fase de terminação em confinamento, o maior ganho de peso, melhor conversão alimentar e melhor acabamento de carcaça podem ser obtidos utilizando animais resultantes de processos de seleção genética. Animais com maior desempenho produtivo em confinamento consomem mais alimentos e, consequentemente emitem mais metano por dia $(\mathrm{g} / \mathrm{dia})$, no entanto, se forem consideradas as emissões por quilo de alimento ingerido e por quilo de ganho de peso, não foram afetadas pelo maior desempenho dos animais da linhagem Nova. 


\section{CONSIDERAÇÕES FINAIS}

O estudo de diferentes linhagens dentro de uma mesma raça é válido já que linhagens melhoradas podem apresentar diferentes desempenhos, emissões de metano e características de carcaça.

O programa de melhoramento genético aplicado no rebanho experimental da raça Canchim na Embrapa Pecuária Sudeste vem sendo efetivo ao longo do tempo, já que os resultados apresentados neste estudo indicam o progresso genético nas diferentes linhagens.

Novos estudos devem ser realizados para avaliar o desempenho, características de carcaça e emissões das diferentes linhagens da raça Canchim, considerando que maiores divergências são esperadas com o avanço do programa de melhoramento genético da raça. 


\section{REFERÊNCIAS BIBLIOGRÁFICAS}

ASSOCIAÇÃO BRASILEIRA DO AGRONEGÓCIO - ABAG. Confinamento bovino deve recuar no Brasil. Disponível em: http://www.abag.com.br/sala imprensa/interna/abag-confinamento-bovino-deve-recuar-no-brasil. Acesso: 19 de outubro de 2016.

ASSOCIAÇÃO BRASILEIRA DAS INDUSTRIAS EXPORTADORAS DE CARNEABIEC. Perfil da pecuária no Brasil, Relatório anual. Disponível em: http://www.abiec.com.br/Sumario.aspx, Acesso: 10 de novembro de 2016.

ASSOCIAÇÃO BRASILEIRA DE CRIADORES DE CANCHIM-ABCCAM. A Raça Canchim. Disponível em: http://www.abccan.com.br/canchim/index.php/a-raca.html, Acesso: 10 de novembro de 2016.

ALENCAR, M.M.; CORRÊA, L.A.; GODOY, R.; COSTA, J.L. Desenvolvimento de animais Canchim me Nelore em regime de pasto. Pesquisa Agropecuária Brasileira, v. 24, p. $1335-1338,1989$.

ALENCAR, M. M; OLIVEIRA, J. A. L; LIMA, R.; BARBOSA, P. F. Peso ao nascimento à desmama e ao sobreano de animais Nelores e cruzados Canchim x Nelore. In: REUNIÃO ANUAL DA SOCIEDADE BRASILEIRA DE ZOOTECNIA, 31., 1994. Maringá - PR. Anais... Maringá: SBZ. 1994. p. 151.

ALENCAR, M.M. Pesquisa na Raça Canchim. In: III CONVENÇÃO NACIONAL DA RAÇA CANCHIM, 3 1997. Anais... São Carlos: Embrapa-CPPSE/São Paulo ABCCAN. 1997. p. 77-91.

ALENCAR, M.M. A Raça Canchim. In: SIMPÓSIO PECUÁRIA, PERSPECTIVAS PARA O III MILÊNIO, 1, 2000. Anais... Pirassununga: FZEA-USP. 2000. CD-ROM

ALENCAR, M.M.; BARBOSA, P.F. Formação de populações compostas. In: SIMPÓSIO BRASILEIRO SOBRE CRUZAMENTO DE BOVINOS DE CORTE, 1, 2003, Anais... Londrina: IAPAR, 2003 CD-ROM.

ALMEIDA, R. G., \& MEDEIROS, S. R. Emissão de gases de efeito estufa em sistemas de integração lavoura-pecuária-floresta. In: SISTEMAS AGROFLORESTAIS E DESENVOLVIMENTO SUSTENTÁVEL: 10 ANOS DE PESQUISA, 2013 Anais... Campo Grande: Embrapa Gado de Corte, 2013. 
ARCHER, J. A.; RICHARDSON, E.C.; HERD, R.M.; ARTHUR, P.F. Potential for selection to improve efficiency of feed use in beef cattle: a review. Crop and Pasture Science, v. 50, n. 2, p. 147-162, 1999.

ALLEE, W.C.; PARK, O.; EMERSON, A.E.; PARK, T.; SHIMIDT, K.P. Principles of animal ecology. WB Saundere Co. Ltd., 1949.

AZEVÊDO, J.A.G.; VALADARES FILHO, S.C.; PINA, D.S.; VALADARES, R.F.D.; DETMANN E. Predição de consumo de matéria seca por bovinos de corte em confinamento. Exigências Nutricionais de Bovinos Puros e Cruzados - BRCORTE, 2010.

BARBERO, R.P.; BARBOSA, M.A.A.F.; CASTRO, L.M.; RIBEIRO, E.L.A.; MIZUBUTI, I.Y.; BUMBIERIS JUNIOR, V.H.; SILVA, L.D.F.; MASSARO JUNIOR, F.L. Desempenho de novilhos de corte em pastos de capim-Tanzânia sob quatro alturas de desfolha. Arquivo Brasileiro de Medicina Veterinária e Zootecnia, v.66, n.2, p.481-488, 2014.

BARICHELLO, F. Estimativas de parâmetros genéticos para escores de avaliação visual, peso e perímetro escrotal à desmama de bovinos da raça Canchim. Dissertação (Genética e Melhoramento Animal) - Faculdade de Ciências Agrárias e Veterinárias - Unesp/Jaboticabal, p. 81, 2007.

BERNDT, A.; TOMKINS, N.M. Measurement and mitigation of methane emissions from beef cattle in tropical grazing systems: a perspective from Australia and Brazil. The Animal Consortium, v.7: s. 2 p. 363-372, 2013.

BERNDT, A.; BOLAND, T.; DEIGHTON, M. H.; GERE, J. I.; GRAINGER, C.; HEGARTY, R. S.; IWAASA, A. . Guidelines for use of Sulphur hexafluoride (SF6) tracer technique to measure enteric methane emissions from ruminants. 1. ed. Wellington: Ministry for Primary Industries, v.1 p.166, 2014.

BLAXTER, K. L.; CLAPPERTON, J. L. Prediction of the amount of methane produced by ruminants. British Journal of nutrition, v. 19, n. 01, p. 511-522, 1965.

CANO, C.C.P.; CECATO, U.; CANTO, M.W.; RODRIGUES, A.B.; JOBIM, C.C.; RODRIGUES, A.M.; GALBEIRO, S.; NASCIMENTO, W.G. Produção de forragem do capim-Tanzânia (Panicum maximum Jacq. Cv. Tanzânia-1) pastejado em diferentes alturas. Revista Brasileira de Zootecnia, v.33, n.6, p1949-1948, 2004. 
CASSANDRO, M.; CECCHINATO, A.; BATTAGIN, M.; PENASA, M. Genetic parameters of predicted methane production in Holstein Friesian cows. In: Proceedings... 9th World Congress on Genetics Applied to Livestock Production, Leipzig, Germany, 2010.

CASSANDRO, M. Comparing local and cosmopolitan cattle breeds on added values for milk and cheese production and their predicted methane emissions. Animal Genetic Resources, 2013. Disponível em: CJO2013. doi:10.1017/S2078 $63361200077 X$.

CAVANAGH, A.; MCNAUGHTON, L.; CLARK, H.; GREAVES, C.; GOWAN, J.M.; PINARES-PATIÑO, C.; DALLEY, D.; VLAMING, B.; MOLANO, G. Methane emissions from grazing Jersey $\times$ Friesian dairy cows in mid lactation. Australian Journal of Experimental Agriculture. v. 48 p. 230-233, 2008.

CHAVES, C.H.C.; CÉZAR, R.T.; SIMÕES, F.S.; TORAL, F.L.B.; ALENCAR, M.M.; BARBOSA, P.F. Parâmetros e tendências genéticas para características de crescimento de bovinos da raça Canchim. In: Anais... XIX Reunião da associação latino-americana de produção animal, 2005.

CREWS, D.H.; LOWERISON, M.; CARON, N.; KEMP, R.A. Genetic parameters among growth and carcass traits of Canadian Charolais cattle. Canadian Journal of Animal Science, v. 84, n. 4, p. 589-597, 2004.

DI MARCO, O.N. Crescimento de bovinos de corte. UFRGS, 2007.

DOLEZAL H.G.; SMITH G.C.; SAVELL J.W.; CARPENTER Z.L. Comparison of subcutaneous fat thickness, marbling and quality grade for predicting palatability of beef. Journal of Food Science. v. 47, p. 397-401, 1982

DONOGHUE, K. A.; BIRD-GARDINER, T.; ARTHUR, P.F.; HERD, R.M.; HEGARTY, R.F. Genetic and phenotypic variance and covariance components for methane emission and postweaning traits in Angus cattle. Journal of Animal Science, v.94, n.4, p.1438-1445, 2016.

FERNADES, A.R.M.; SAMPAIO, A.A.M.; HENRIQUE, W.; PERECIN, D.; OLIVEIRA, E.A.; TÚLLIO, R.R. Avaliação econômica e desempenho de machos e fêmeas em confinamento alimentados com dietas à base de silagem de milho e concentrado ou 
cana-de-açúcar e concentrado contendo grão de girassol. Revista Brasileira de Zootecnia, v. 36, p. 855-864, 2007.

FOOD AND AGRICULTURE ORGANIZATION OF THE UNITED NATIONS-FAO. Global survey of agricultural mitigation projects. Mitigation of Climate Change in Agriculture Series 1. Rome. p. 38, 2010.

FOOD AND AGRICULTURE ORGANIZATION OF THE UNITED NATIONS. YEARBOOK, FAO Statistical. World food and agriculture. Food and Agriculture Organization of the United Nations, Rome, p. 2013, 2013.

FOOD AND AGRICULTURE ORGANIZATION OF THE UNITED NATIONS-FAO. Tackling climate change through livestock. A global assessment of emissions and mitigation opportunities. Roma/Italia: FAO, 115p. 2013.

GOULART, R.S.; Almeida, R.; Pott, E.B. Desempenho de bovinos Nelore e cruzados "Bos taurus" x Nelore recriados em pastagem e terminados em confinamento. In: REUNIÃO ANUAL DA SOCIEDADE BRASILEIRA DE ZOOTECNIA, Anais... João Pessoa: Sociedade Brasileira de Zootecnia, 2006.

GRAINGER, C.; BEAUCHEMIN, K. A. Can enteric methane emissions from ruminants be lowered without lowering their production? Animal Feed Science and Technology, v. 166, p. 308-320, 2011.

HAMMOND, K. J.; CROMPTON, L. A.; BANNINK, A.; DIJKSTRA, J.; YÁÑEZ-RUIZ, D.R.; O'KIELY, P.; SCHWARM, A. Review of current in vivo measurement techniques for quantifying enteric methane emission from ruminants. Animal Feed Science and Technology. 2016.

HEGARTY, R.S.; GOOPY, J.P.; HERD, R.M.; MCCORKELL, B. Cattle selected for lower residual feed intake have reduced daily methane production. Journal of Animal Science. v. 85 p.1479-1486, 2007.

HERD, R. M.; ARTHUR, P.F.; DONOGHUE, K.A.; BIRD, S.H.; BIRDO-GARDINIER, T.; HEGARTY, R.S. Measures of methane production and their phenotypic relationships with dry matter intake, growth, and body composition traits in beef cattle. Journal of Animal Science, v. 92, n. 11, p. 5267-5274, 2014. 
HRISTOV, A.N.; OH, J.; LEE, C.; MEINEN, R.; MONTES, F.; OTT, T.; FIRKINS, J.; ROTZ, A.; DELL, C.; ADESOGAN, A. Nutritional and management strategies to mitigate greenhouse gas emissions. In: Proceedings $201324^{\text {th }}$ annual Florida ruminant nutrition symposium, 5-6 February 2013, Gainesville, 2013, p.90-98.

HRISTOV, A.N.; OH, J.; GIALLONGO, F.; FREDERICK, T.; WEEKS, H.; ZIMMERMAN, P.R.; HRISTOVA, R.A.; ZIMMERMAN, S.R.; BRANCO, A.F. The use of an automated system (GreenFeed) to monitor enteric methane and carbon dioxide emissions from ruminant animals. JoVE (Journal of Visualized Experiments). v. 103, e52904,http://dx.doi.org/10.3791/52904. 2015

HERRING, W.O.; MILLER, D.C.; BERTRAND, J.K. Evaluation of machine, technician, and interpreter effects on ultrasonic measures of backfat and longissimus muscle area in beef cattle. Journal of Animal Science. v.72, p.2216-2226, 1994.

INTERGOVERNMENTAL PANEL ON CLIMATE - IPCC. Guidelines for national greenhouse gas inventories. IPCC 2006, 2006. Disponível em: http://www. ipcc-nggip. iges. or. jp./public/2006gl/index. html

JARDINE, C.N.; BOARDMAN, B.; OSMAN, A.; VOWLES, J.; PALMER, J. methane UK. The Environmental Change Institute, 2004. Methane UK 2012. Disponível em: http://www.eci.ox.ac.uk/research/energy/methaneuk.php, Acesso: 12 de novembro de 2016.

JOHNSON, K.; HURLEY, M.; WESTBERG, H.; LAMB, B.; ZIMMERMAN, P. Measurement of methane emissions from ruminant livestock using a sulfur hexafluoride tracer technique. Environmental Science \& Technology, v. 28, n. 2, p. 359-362, 1994.

JOHNSON, K.A.; JOHNSON, D.E. Methane emissions from cattle. Journal of Animal Science. v. 73, p. 2483-2492, 1995.

KARNATI, S.K.R.; YU, Z.; FIRKINS, J.L. Investigating unsaturated fat, monensin or bromoethanesulfonate in continuous cultures retaining ruminal protozoa. II. Interaction of treatment and presence of protozoa on prokaryotic communities. Journal of Dairy Science. v. 92 p.3861-3873, 2009.

KELLNER, O.J. The Scientific Feeding of Animals. Duckworth, London, 1913. 
KIRCHGESSNER, M.; WINDISCH, W.; MULLER, H.I.; KREUZER, M. Release of methane and of carbon dioxide by dairy cattle. Agribiological Research (Germany, FR), 1991.

KOCH, R.M.; SWIGER, L.A.; CHAMBERS, D.; GREGORY, K.E. Efficiency of feed use in beef cattle. Journal of Animal Science, v. 22, n. 2, p. 486-494, 1963.

$L A L$, R. Soil carbon sequestration impacts on global climate change and food security. Science, v. 304, n. 5677, p. 1623-1627, 2004.

LOBATO, J.F.P.; FREITAS, A.K.; DEVINCENZI, T.; CARDOSO, L.L.; TAROUCOI, J.U.; VIEIRA, R.M.; DILLENBURG, D.R.; CASTRO, I. Brazilian beef produced on pastures: Sustainable and healthy. Meat Science, v. 98, n. 3, p. 336-345, 2014.

MENEZES, L.F.G.; BRONDANI, I.L.; ALVES FILHO, D.C.; RESTLE, J., ARBOITTE, M.Z.; FREITAS, L.S.; PAZDIORA, R.D. Características da carcaça de novilhos de diferentes grupos genéticos, terminados em confinamento, recebendo diferentes níveis de concentrado. Ciência Rural, Santa Maria. V. 35, p. 1141-1147, 2005.

MERCADANTE, M.E.Z.; CALIMAN, A.P.M.; CANESIN, R.C.; BONILHA, S.F.M.; BERNDT, A.; FRIGHETTO, R.T.S.; MAGNANI, E.; BRANCO, R.H. Relationship between residual feed intake and enteric methane emission in Nellore cattle. Revista Brasileira de Zootecnia, v. 44, n. 7, p. 255-262, 2015.

MINISTÉRIO DA CIÊNCIA, TECNOLOGIA E INOVAÇÃO-MCTI. Estimativas anuais de emissões de gases de efeito estufa no Brasil, v. 2 p. 161, 2014.

MOSS, A. R.; GIVENS, D. I.; GARNSWORTHY, P. C. The effect of supplementing grass silage with barley on digestibility, in sacco degradability, rumen fermentation and methane production in sheep at two levels of intake. Animal Feed Science and Technology, v. 55, n. 1-2, p. 9-33, 1995.

MOTT, G. O.; LUCAS, H. L. The design, conduct and interpretation of grazing trials on cultivated and improved pastures. In: Proceedings... International grassland congress. 1952, p. 1380-1395.

NKRUMAH, J.D.; OKINE, E.K.; MATHISON, G.W.; SCHMID, K.; LI, C.; BASARAB, J.A.; PRICE, M.A.; WANG, Z.; MOORE, S.S. Relationships of feedlot feed efficiency, 
performance, and feeding behavior with metabolic rate, methane production, and energy partitioning in beef cattle. Journal of Animal Science. v. 84, p.145-153, 2006. O`MARA, F. P. The significance of livestock as a contributor to global greenhouse gas emissions today and in the near future. Animal Feed Science and Technology. 166167, 7-15, 2011.

OLIVEIRA SILVA, R.; BARIONI, L.G.; HALL, J.A.J.; FOLEGATTI MATSUURA, M.; ZANETT ALBERTINI, T.; FERNANDES, F.A.; MORAN, D. Increasing beef production could lower greenhouse gas emissions in Brazil if decoupled from deforestation. Nature Climate Change, 2016.

PEACOCK, F.M. et al. Breed and heterosis effects on carcass characteristics of Angus, Brahman, Charolais and crossbred steers. Journal of Animal Science, v.49, n.2, p.391-397, 1979.

POTT, E.B., PAINO, C.R.S., ALENCAR, S.B. III Convenção Nacional da Raça Canchim. Anais.... São Carlos: Embrapa-CPPSE/São Paulo ABCCAN, 1997. p. 108.

POULSEN, M.; SCHWAB, C.; JENSEN, B.B.; ENGBERG, R.M.; SPANG, A.; CANIBE, N.; HØLBETG, O.; MILINOVICH, G.; FRAGNER, L.; SCHLEPER, C.; WECKWERTH, W.; LUND, P.; SCHRAMM, A.; URICH, T. Methylotrophic methanogenic Thermoplasmata implicated in reduced methane emissions from bovine rumen. Nature Communications. V. 4, p. 1428, 2012.

PRIMAVESI, O; BERNDT, A.; LIMA, M.A.; FRIGHETTO, TOYOKO S.R.; DEMARCHI, J.J.A.A.; PEDREIRA, M.S. Produção de gases de efeito estufa em sistemas agropecuários: bases para inventário de emissão de metano por ruminantes. Cap.8.. In: Proceedings... 1, Lima, M.A.; Boddey, R.M.; Alves, B.J.R; Machado, P.L.O.A.V; Urquiaga, S. (Org.). Estoques de C e Emissões de Gases de Efeito Estufa na Agropecuária Brasileira. 1ed.Brasília, DF: Embrapa, 2002.p. 239-270.

RICCI, P.; CHAGUNDA, M.G.G.; ROOKE, J.; M HOUDIJK, J.G.; DUTHIE, C.A.; HYSLOP, J.; WATERHOUSE, A. Evaluation of the laser methane detector to estimate methane emissions from ewes and steers. Journal of Animal Science, v. 92(11), p. 5239-5250, 2014.

RUBIANO, G.A.G.; ARRIGONI, M.B.; MARTINS, C.L.; RODRIGUES, E.; GONÇALVES, H.C.; ANGERAMI, C.N. Desempenho, características de carcaça e 
qualidade da carne de bovinos superprecoces das raças Canchim, Nelore e seus mestiços. Revista Brasileira de Zootecnia, v. 38, p. 2490-2498, 2009.

RUSSELL, J.B.; WALLACE, R.J. Energy-yielding and energy-consuming reactions. In: Proceedings... P.N. Hobson and C.S. Stewart, eds. The Rumen Microbial Ecosystem, London, U.K., Blackie Academic \& Professional. 1997. p. 246-282.

RUSELL, J.R.; BISINGER, J.; POWERS, W.J. Grazing system effects methane emissions from cows in southern lowa pasture. Animal Industry Report, v. 662, p. 53, 2016.

SAKAMOTO, L.S.; BERNDT, A.; LEMES, A.P.; MAHLMEISTER, K.; VILLAS-BOAS, D.F.; MÉO, P.; PEZZOPANE, J.R.M.; ESTEVES, S.N.; BERNARDI, A.C.C.; PEDROSO, A.F.; ALVES, T.C.; OLIVEIRA, P.A. Enteric methane emissions of Canchim steers in five crop-livestock-forest integrated system. In: Proceedings... World Congress on Integrated Crop-Livestock-System, Brasilia, 2015.

SHIBATA, M., TERADA, F. Factors affecting methane production and mitigation in ruminants. Animal Science Journal, v. 81, n. 1, p. 2-10, 2010.

SOUSSANA, J.F.; TALLEC, T.; BLANFORT, V. Mitigating the greenhouse gas balance of ruminant production systems through carbon sequestration in grasslands. Animal, v. 4, n. 03, p. 334-350, 2010.

STATISTICAL ANALYSIS SYSTEM INSTITUTE. SAS/STAT. Guide of personal computers. Version 9.3. Inc., Cary, NC

STEINFELD, H.; GERBER, P.; WASSENAAR, T.; CASTEL, V.; ROSALES, M.; HAAN, C. Livestock's long shadow: environmental issues and options. Food and Agriculture Organization of the United Nations, 2006.

TATUM, J.D.; SMITH, G.C.; CARPENTER, Z.L. Interrelationships between marbling, subcutaneous fat thickness and cooked beef palatability Journal of Animal Science. v. 54, p. 777-784, 1982.

TEKIPPE, J.A.; HRISTOV, A.N.; HEYLER, K.S.; CASSIDY, T.W.; ZHELJAZKOV, V.D.; FERREIRA, J.F.S.; KARNATI, S.K.; VARGA, G.A. Rumen fermentation and production effects of Origanum vulgare $L$. leaves in lactating dairy cows. Journal of Dairy Science. V. 94 p. 5065-5079, 2011. 
TREMATORE, R.L.; ALENCAR, M.M.; BARBOSA, P.F.; OLIVEIRA, A.L.; ALMEIDA, M.A. Estimativas de efeitos aditivos e heteróticos para características de crescimento pré-desmama em bovinos Charolês-Nelore. Revista Brasileira de Zootecnia, v. 27, n. 1 , p. 87-94, 1998.

UNITED STATES DEPARTMENT OF AGRICULTURE (USDA), 2016. Livestock and Poultry: World Markets and Trade. Disponível em: http://apps.fas.usda.gov/psdonline/circulars/livestock_poultry.pdf Acesso: 26 de julho de 2016.

VAN SOEST, Peter J. Nutritional ecology of the ruminant. Cornell University Press, 1994.

VEERKAMP, R.F. Feed intake and energy balance in lactating animals. Communication. In: Proceedings... $7^{\text {th }}$ World Congress on Genetics Applied to Livestock Production, Montpellier, France, 2002. p. 10-01.

VIEIRA, P.F. Estudo comparativo sobre a recria de bovinos de corte submetidos a diferentes regimes de alimentação em confinamento e pastagem. Dissertação de Mestrado, Escola Superior de Agricultura Luiz de Queiroz, 1975.

VLAMING, J.; LOPEZ-VILLALOBOS, N.; BROOKES, I.; HOSKIN S.; CLARK, H. Within and between animal variance in methane emissions in non-lactating dairy cows. Australian Journal of Experimental Agriculture. v. 48 p. 124-127, 2008.

WANG, L.A.; GOONEWARDENE, Z. The use of MIXED models in the analysis of animal experiments with repeated measures data. Canadian Journal of Animal Science. v.84, p.1-11, 2004.

WASHBURN, L.E.; BRODY, S. Growth and development XLII. Methane, hydrogen, and carbon dioxide production in the digestive tract of ruminants inrelation to the respiratory exchange. In: Proceedings... Mumford, F.B. (Ed.), Growth and Development. Univesrity of Missouri, Colombia, Missouri. 1937.

WESTBERG, H. H.; JOHNSON, K. A.; COSSALMAN, M. W.; MICHAEL, J. J. A SF6 tracer technique: Methane measurement from ruminants. In: USEPA - Evaluating ruminant livestock efficiency projects and programs. Washington State University, Pullman, Washington. p. 40. 1998. 
YOKOO M.J.; ALBUQUERQUE L.G.; LÔBO R.B.; BEZERRA L.A.F.; ARAUJO F.R.C.; SILVA J.A.V.; SAINZ R.D. Genetic and environmental factors affecting ultrasound measures of longissimus muscle area and backfat thickness in Nelore cattle. Livestock Science, v. 117, p.147-154, 2008

ZIMMERMAN, P.R., System for measuring metabolic gas emissions from animals. United States Patent number US005265618A. 1993.

ZIMMERMAN, P.R.; ZIMMERMAN, R.S. Method and system for monitoring and reducing ruminant methane production. United States Patent numberUS20090288606 A1. 2012. 